\title{
HOW MUCH DIVERSITY IS DIVERSITY?
}

\author{
Ashley Michelle Guidroz
}

\author{
A Dissertation \\ Submitted to the Graduate College of Bowling Green \\ State University in partial fulfillment of \\ the requirements for the degree of

\section{DOCTOR OF PHILOSOPHY}

March: 2008

Committee:

Scott Highhouse, Advisor

Margaret E. Brooks

Graduate Faculty Representative

Jennifer Z. Gillespie

Mary Hare 
(C) 2008

Ashley Michelle Guidroz

All Rights Reserved 


\begin{abstract}
Scott Highhouse, Advisor

The role that diversity plays in the workplace has increased over time as more companies adopt diversity management strategies in an effort to increase performance or attract new employees (Hays-Thomas, 2004). Little research has been directed, however, toward understanding how diversity perceptions are impacted by the amount of diversity present in the group. It is easy to identify occurrences when diversity is absent, but we know little about how much diversity is needed for a group to be perceived as diverse (Harrison \&Klein, 2007). Drawing largely from research on judgment and decision making (Bazerman, 1993; Levin, Schneider, \& Gaeth, 1998; Tversky \& Kahneman, 1981) this paper examined how the amount of diversity present and the way the diversity information is framed can influence people's perceptions of group diversity. These questions were examined in the context of two types of demographic diversity: gender and race. Results indicated that people perceived racial/ethnic diversity, described as the "proportion of Blacks and Hispanics" in the workplace, as being more consistent with their idea of diversity and viewed the organization as making more effort toward managing diversity than when diversity was framed in any other population (i.e., women, men Whites). Participants also demonstrated a preference for equality and judged the organization to be most successful at managing diversity when the minority and non-minority groups held an equal proportion in the population (i.e., $50 \%$ ).
\end{abstract}


This dissertation is dedicated to my mother, Robin, who never tires of parenting, cheerleading, and supporting all of her children in their endeavors. 


\section{ACKNOWLEDGMENTS}

I am grateful to my advisor, Dr. Scott Highhouse, for his support and direction throughout the course of this project. I would like to thank my committee members, Drs Jennifer Gillespie, Mary Hare, and Margaret Brooks for their thoughtful contributions and insights. Most importantly, I would like to thank my father, Jim, for his wisdom, my mother, Robin, for her support, and my family, Justin, Ryan, and Elaine, for always believing in me. I am grateful to Tyler and Andrew for serving as the perfect distractions in between drafts and I am grateful for all my family in Louisiana who share in the joy of this accomplishment. Lastly, I am so thankful for the support of all of my friends both in and outside of Bowling Green. Your support - no matter how big or small - has meant the most. Thank you all! 


\section{TABLE OF CONTENTS}

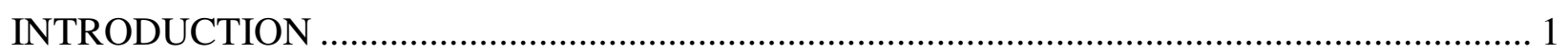

Making the Case for Diversity ......................................................................... 3

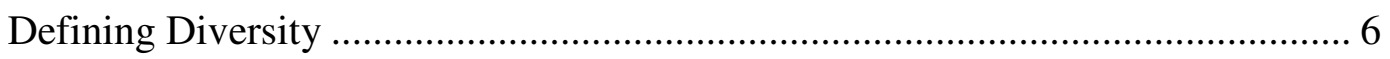

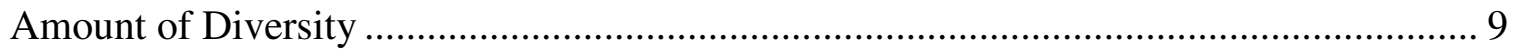

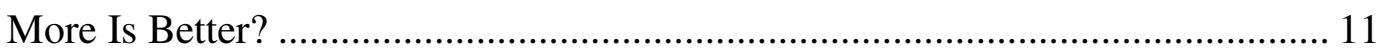

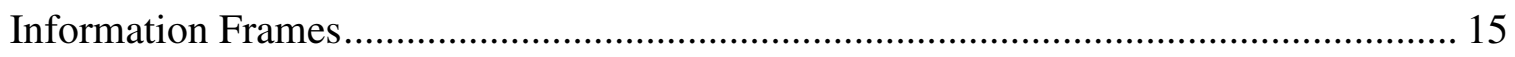

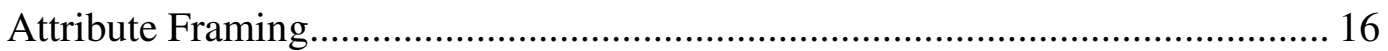

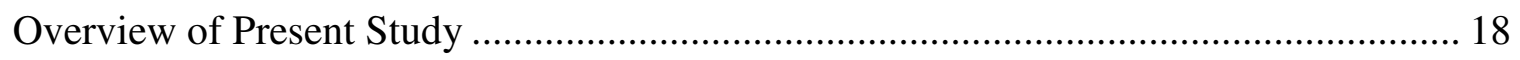

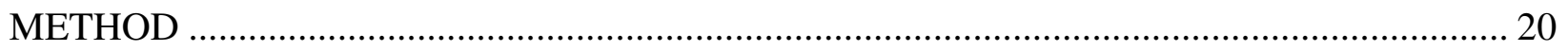

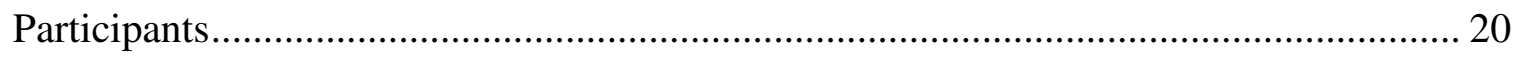

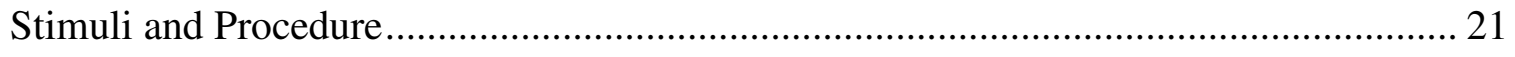

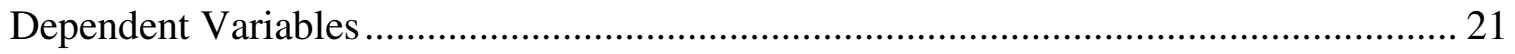

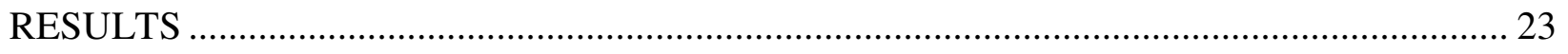

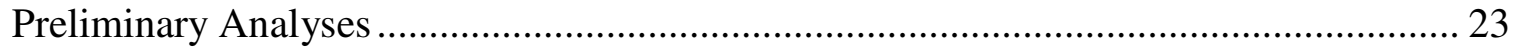

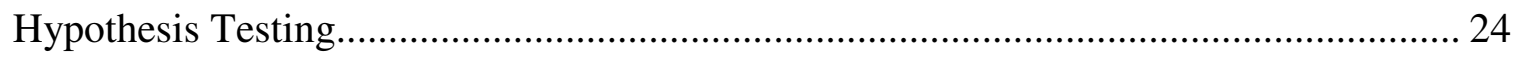

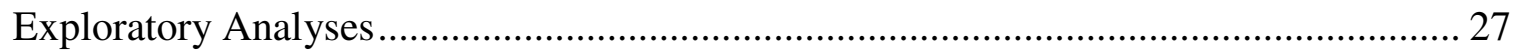

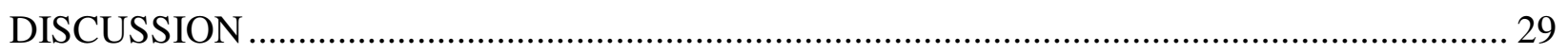

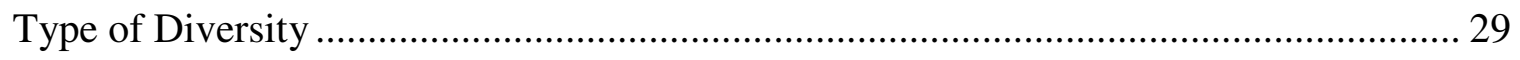

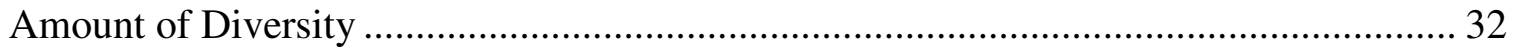

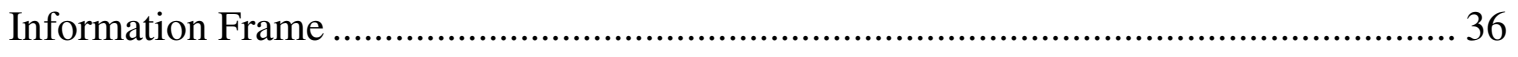

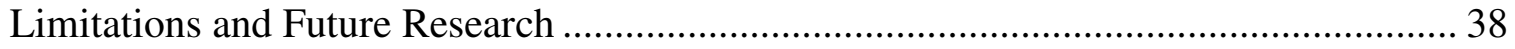

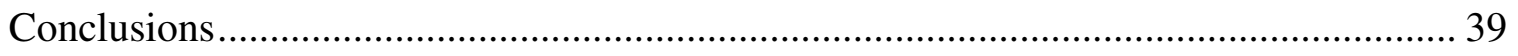




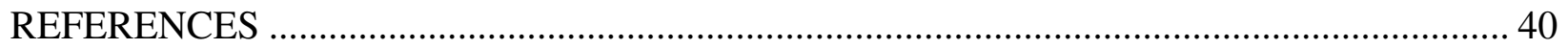

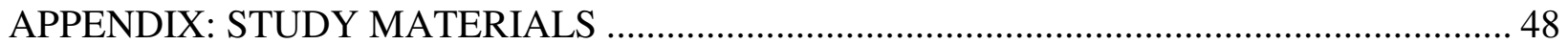




\section{LIST OF TABLES}

Table

Page

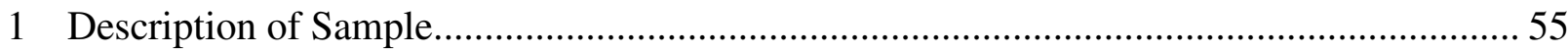

2 Results of Principal Axis Factoring on Dependent Variables .......................................... 56

3 Means, Standard Deviations, and Intercorrelations between Study Variables .................... 57

4 Summary of Analysis of Covariance for Judgments on Conception of Diversity............... 58

5 Cell Means for Information Frame and Diversity Type on Conception of Diversity........... 59

6 Summary of Analysis of Covariance for Judgments on Diversity Management Efforts ..... 60

7 Tests of Linear and Quadratic Trends of Amount of Diversity on Diversity Management

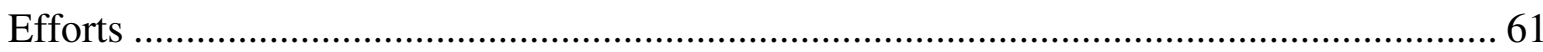

8 Cell Means of Information Frame and Diversity Type on Diversity Management Effort ... 62

9 Mean Estimates of U.S. Population Base-Rates by Condition ........................................ 63

10 Summary of Analysis of Covariance for Judgments of Diversity Management Efforts with Estimates of Population Base-Rates Included as Covariates 


\section{LIST OF FIGURES}

Figure

Page

1 Graph of Interaction between Type of Diversity and Information Frame on Conception of

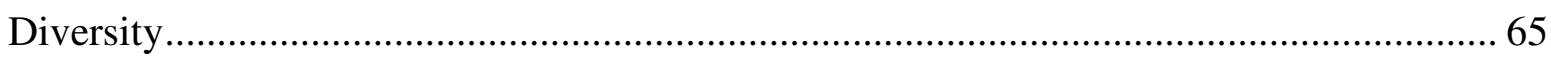

2 Graph of Main Effect of Amount of Diversity on Diversity Management Effort .............. 66

3 Graph of Interaction between Type of Diversity and Information Frame on Diversity Management Effort . 


\section{INTRODUCTION}

Diversity is generally defined as the existence of differences among members of a social unit (Jackson, May \& Whitney, 1995). The language of diversity which was once so heavily dominated by phrases like "affirmative action" or "equal opportunity" has now been replaced by “diversity management" or "outreach recruitment” (Schwartz, 1996). Organizations have made their commitment to diversity evident in their business practices, marketing, and selection of diverse employees. A 2001 survey of HR professionals indicated that most believed their company's diversity initiatives improved the organization's culture, employee recruitment, and relations with clients, and also positively impacted creativity and productivity (Bowl, 2001). For example, at any Starbucks location, one can find a pamphlet outlining the corporation's principles of "embrace[ing] diversity as an essential component in the way we do business" (Starbucks Coffee Company, 2005). The pamphlet contains a demographic breakdown of the Starbucks board of directors and executive team, emphasizing the number of women and people of color who hold these positions, as well as a summary of the diversity management programs that are provided to Starbucks employees.

A problem inherent within the study of diversity, however, is the abundance of theoretical perspectives that have clouded the definition of the concept (Harrison \& Klein, 2007). Diversity literature has moved beyond basic operationalizations of diversity as solely being one's race, gender, or ethnicity to include less visible types such as personality or job attitudes (HaysThomas, 2004). Although expanding the definition provides more avenues for organizations to pursue, this has contributed little to furthering our understanding of diversity. Drawing largely from research on judgment and decision making (Bazerman, 1993; Levin, Schneider, \& Gaeth, 1998; Tversky \& Kahneman, 1981) this paper will examine how the amount of diversity present 
and the way the diversity information is framed can influence people's perceptions of group diversity (e.g., conception of what the term “diversity” means, judgments about an organization's efforts at managing diversity) and how this may interact with the type of diversity. These questions are important for guiding theory about the role that diversity plays in organizational processes. Understanding what amount of group diversity is perceived as fair or psychologically meaningful to viewers can enhance the ability of researchers and practitioners to promote diversity in the workplace.

It is easy to identify occurrences when diversity is absent; however, we know little about how much diversity is needed for a group to be considered diverse (Harrison \&Klein, 2007). Specifically, this paper hypothesizes that judgments regarding amount of diversity will reflect an insensitivity to base rates in the population. Consequently, people will utilize an equality heuristic when forming judgments and assume group membership should be evenly distributed between minority and non-minority groups. This paper also hypothesizes an effect of attributional framing on perceptions of diversity. The judgment and decision making (JDM) literature is replete with examples of the effect of attribute framing on choice and has shown that changing the description of a choice, such as in terms of success versus failure, can yield different perceptions (e.g., Levin, Schneider, \& Gaeth, 1993). Diversity information framed in terms of the minority population, such as the percentage of diverse applicants hired, may convey a different meaning than when framed as the percentage of non-diverse applicants hired. This literature will be reviewed in light of its effects on judging group diversity.

I begin with a discussion of the role that diversity plays in the workplace. The history of workplace diversity is rooted in the civil rights legislation of the 1970's but arguments have been made for the importance of diversity to the attraction and recruitment of minority candidates, as 
well as to the overall profitability of the company. Also, an inherent problem within the diversity literature is the abundance of theories defining diversity. An analysis of all diversity theories is beyond the scope of this paper; however, this paper contributes to this discussion by examining how contextual variables, such as the type of diversity, the proportion of minority presence, and the way in which diversity information is framed can influence people's conception of diversity and judgments about the organization's efforts at managing diversity. Specifically, the outcomes that this study will focus on are what people think of when they think about “diversity", labeled Conception of Diversity, and people's judgments of an organization's efforts to manage diversity, labeled Diversity Management Efforts.

\section{Making the Case for Diversity}

Diversity and diversity management practices have become more prevalent in workplaces across America for a variety of reasons. Diversity research has a long and close relationship with the legal and social policy community, dating back to the earliest civil rights legislation passed in the1960's (Hays-Thomas, 2004). The passage of the Civil Rights Act of 1964, and additional legislation to protect older workers (Age Discrimination in Employment Act, 1967) and those with disabilities (Americans with Disabilities Act, 1990) have helped define diversity in America through the establishment of protected classes (e.g., race, sex, national origin). Although such legislation was needed to ensure equal access to employment for all Americans, it also served the purpose of defining diversity by symbolizing what characteristics of American workers should be preserved in the workplace. In this regard, organizations have relied on policies, such as the $4 / 5$ ths rule, for ensuring that selection tools do not unfairly discriminate against minority applicants. 
Organizations have also made a business case for diversity, arguing that diversification of the workplace is a necessity for increasing workplace innovation and creativity (Cox \& Blake, 1991; McLeod, Lobel, and Cox, 1996). Researchers have suggested that effective diversity management can lower organizational costs in terms of grievances, lawsuits, employee turnover, and ineffectiveness due to poor communication and dissatisfaction (Cox, 1997). The business necessity argument was also made during the United States Supreme Court case of Gratz v. Bollinger (2003). In this case the University of Michigan's admissions practices were challenged for automatically awarding minority applicants "diversity points" that were not available for non-minority applicants. A number of organizations filed amicus curiae briefs supporting the University of Michigan's policies because promoting diversity in higher education would increase the pool of highly qualified applicants for future personnel selection. Arguments raised in the briefs were that students educated around diversity (1) are more adept at facilitating unique and creative approaches to problem solving; (2) are better able to develop products that appeal to a wide variety of consumers; (3) are better equipped for working with diverse business partners, employees, and clientele and; (4) will contribute to a positive work environment through decreasing incidents of discrimination and stereotyping (3M et al., 2003; General Motors, 2003; Media Companies, 2003; MTV Networks, 2003).

Although the argument is compelling, connecting workplace diversity to positive organizational outcomes has yielded inconsistent results. Studies have found both a positive (e.g., Bantel \& Jackson, 1989; Cummings, 2004; Lee \& Farh, 2004) and a negative diversityperformance relationship (e.g., Ely, 2004; Milliken \& Martins, 1996; Williams \& O’Reilly, 1998). Others have found no relationship at all (e.g., Kochan, Bezrukova, Ely, Jackson, Joshi, Leonard, Levine, \& Thomas, 2003). Reviews of the diversity-performance literature have 
concluded that, although group diversity does lead to a combination of positive and negative outcomes, the effects are small (Bowers, Pharmer, \& Salas, 2000; Jackson, Joshi, \& Erhardt, 2003; Webber \& Donahue, 2001). Even categorizing diversity according to its job-relatedness does not produce more consistent relationships with workplace outcomes, such as group cohesion or performance (Webber and Donahue, 2001).

The relationship between diversity and organizational outcomes is inconsistent. Nevertheless, diversity can still be important from an organizational image perspective because of the advantage it provides in attracting and recruiting minority employees (e.g., Avery, 2003; Gilbert \& Stead, 1999; Ng \& Burke, 2005). As ethnic minority groups constitute a larger percentage of the U.S. population so does the number of consumer dollars that are controlled by members of these groups. It is believed that employers who hire minorities may increase their appeal to these markets (Hays-Thomas, 2004). Additionally, some research has shown that the appearance of diversity and statements about diversity management can enhance attraction to and perceived fairness of organizations when recruiting minority applicants. In a study of MBA job seekers, women and ethnic minorities indicated that diversity management programs were an important factor in accepting a job offer and people who were high achievers and new immigrants were more attracted to organizations that had a diversity management program (Ng \& Burke, 2005). In another study, Black participants were more attracted to organizations whose recruitment advertisements depicted a balance between white and black employees, but only when a black employee was portrayed in a supervisory role (Avery, 2003). Lastly, Gilbert and Stead (1999) found that fairness perceptions of minority hires were higher when the selection decision was made under a diversity management program as opposed to an affirmative action program. 
Defining Diversity. In an attempt to establish a link between diversity and organizational outcomes, diversity researchers have proposed a number of types of diversity that could yield consistent, positive relationships with performance. This has led to a problem within the study of diversity resulting in the formation of a wide range of theoretical perspectives defining workplace diversity (Harrison \& Klein, 2007). Researchers are divided on the issue of whether diversity should be conceptualized as a demographic characteristic or viewed as an abstract idea with a limitless number of choices (Hays-Thomas, 2004). In this vein, diversity can be visible, such as race, age, or gender, or can be an underlying trait, such as educational background, job attitudes, or personal values (Ely \& Thomas, 2001; Harrison, Price, \& Bell, 1998; Jackson, May, \& Whitney, 1995; Lau \& Murnighan, 1998, 2005; Pelled, 1996; Tajfel \& Turner, 1986; Turner, 1987).

The U.S. Supreme Court has also contributed to the confusion by grouping together variety in talents or interests with more traditional forms of diversity in higher education. Writing for the majority in Gratz v. Bollinger (2003), Justice William Rehnquist stated that the policy used by the University of Michigan's admissions committee “was not narrowly tailored to achieve the interest in educational diversity that respondents claim justifies their program" (p. 22; Gratz v. Bollinger, 2003). For example, according to Rehnquist, a Caucasian student with extraordinary artistic talent would still only receive five points under the University of Michigan policy, even if the Caucasian student's ability "rivaled that of Monet or Picasso" (p. 24). The court referred to Justice Lewis Powell's opinion in Regents of University of California v. Bakke (1978) where he stated that efforts to improve diversity in academia should focus on individual qualities that are sometimes associated with race but not always dependent upon it. 
Addressing some of the disagreement inherent within the field, Harrison and Klein (2007) proposed a new taxonomy of diversity. In their paper, Harrison and Klein (2007) argued that the construct of diversity is markedly undefined and proposed three characteristics to differentiate between types of diversity. The first type is separation which describes differences in position or opinion among unit members. For example, diversity in work values is an example of separation because it reflects differences in an opinion or position that people hold that are lateral to each other. The second characteristic is variety which defines differences in kind or category. Functional background, such as accountant, engineer, or project manager, is an example of variety because this type of diversity is also categorical. Finally the third characteristic is disparity which describes differences in social assets or resources. Pay or status are two examples of disparity because these types of variables are socially valued assets with an inherent vertical structure.

Missing from their typography is a categorization of demographic diversity. The authors argued that demographic diversity is difficult to categorize because it can be conceptualized as separation or variety or disparity, depending on the context (Harrison \& Klein, 2007). For example, gender can be used in research in a number of different ways that could represent diversity as separation, variety, or disparity. Gender-focused research that asserts that men and women have different sources of knowledge would be an example of the variety type of diversity. Gender can also represent the separation typology when the research question explores whether women hold opposing beliefs to men. Finally, when power is the construct of interest, gender can also be an example of disparity because men historically hold positions at higher levels in the organization than women. This difficulty in categorizing is not limited to just gender; similar problems can also be found when trying to fit tenure, age, or race/ethnicity into 
one typology. Harrison and Klein (2007) concluded that fitting demographic diversity into one of the above typologies is dependent upon the context in which the variable is interpreted.

Even though demographic diversity may be difficult to categorize in Harrison and Klein's (2007) typology, this does not negate the importance of this type of diversity to people's idea of the meaning of diversity or judgments about the effectiveness of an organization's diversity management program. Soni (2000) surveyed employees of a federal agency and found that $45 \%$ of white men, and $18-28 \%$ of minority and/or female respondents endorsed the statement that "Diversity management is the current terminology for affirmative action (p. 399)" indicating that the word 'diversity' is easily associated with historic programs that target demographic minorities. Guidroz and Highhouse (2005) asked participants to rate the effectiveness of a diversity management program and found that approval of the diversity effort varied depending on how the minority population was defined. In their study, the diversity initiative was perceived to be more effective by university undergraduates when the minority population added racial diversity to the organization, as opposed to when it added gender diversity or diversity in educational background.

For these reasons, this paper will limit its focus only to how judgments of demographic diversity, specifically race/ethnicity and gender, are influenced by the amount of diversity and information frames. Previous diversity research has not moved beyond identifying which individual differences will yield the strongest relationship with workplace performance. Because the perception of diversity is just as important, from an appearance and organizational attraction standpoint, as is the relationship of diversity with performance, this paper will focus on how these two types of diversity influence people's conception of diversity. Additionally, there is some research that suggests that people hold different attitudes about race/ethnicity and gender. 
For example, The Gallup Poll (2007) has surveyed American opinions yearly from 2001 to 2006 about the treatment of women, Blacks, and Hispanics and found that respondents are consistently more satisfied with how women are treated than with how Blacks or Hispanics are treated. Soni (2000) asked survey respondents about the quality of interactions between a number of demographic groups and found that more improvement was needed in the interactions between people of different racial/ethnic backgrounds than between males and females. Although gender diversity is important in any workplace these results suggest that increasing racial and ethnic diversity might be rated as a more effective diversity effort because race relations are in a poorer state than gender relations and, hence, race/ethnicity may be more closely associated with people's ideas of diversity than gender.

H1: There will be a main effect for diversity type such that racelethnicity will be perceived as contributing to diversity more than gender.

\section{Amount of Diversity}

Much has been written defining what diversity is, however there has been little discussion directed at quantifying the amount of diversity needed for a group to be viewed as diverse. In judging the diversity of a group it is not difficult to identify situations lacking diversity. We know very little, however, about what proportion minorities should hold for a group to achieve minimum or maximum diversity (Harrison \& Klein, 2007). Knowing this would contribute to our understanding of diversity beyond simply identifying between-person differences. As discussed previously, even the mere perception that a company is diverse can go a long way in attracting and recruiting minority applicants and appealing to minority consumers (Avery, 2003; Gilbert \& Stead, 1999; Hays-Thomas, 2004; Ng \& Burke, 2005). Knowing what proportion the 
minority population should hold in order for a group to be viewed as achieving diversity will enhance the ability of researchers and practitioners to promote diversity in the workplace.

Within diversity research, amount of diversity is often a bi-product of research design, used to compare performance of high versus low-diversity teams. For example, in testing the effects of educational and national diversity in a problem solving task, Dahlin, Weingart, and Hinds (2005) had participants divided into teams and quantified team diversity using Blau's (1977) index ${ }^{1}$. Blau's (1977) index of diversity treats data categorically; diversity is calculated as $1-\Sigma p_{i}{ }^{2}$, where $p_{i}$ is the fraction of team members in category $i$. The Blau index yields a number between 0 and 1, with low numbers indicating less diversity, or more homogeneity in the group. This index is a useful statistic for quantifying diversity empirically, but provides little direction on determining what an appropriate amount of diversity should be, or what amount of diversity is psychologically meaningful to people.

Apart from these empirical studies, there has been little research testing people's perceptions of the appropriate amount of group diversity or whether an organization has made enough effort toward achieving a diverse workforce. Guidroz and Highhouse (2005) presented participants with a description of an organization's new hires varying the proportion of minorities hired at either $5 \%$ or $25 \%$. The organization's diversity efforts were evaluated less favorably when a small fraction of the population was a minority (e.g., 5\%) than when the proportion of minorities was larger (e.g., 25\%). This indicates that people can make distinctions between low and high amounts of diversity but still leaves the question largely unanswered of how much of a workforce should consist of the minority population for the workforce to be judged as diverse.

\footnotetext{
${ }^{1}$ The Blau index is a modified Gini coefficient. The Gini coefficient was originally designed to measure income inequality through a comparison of proportions of group members (Gini, 1921).
} 


\section{More Is Better?}

Discussions of diversity in the popular literature rarely address the issue of proportions in the population. The implicit assumption is that more diversity is better. I would expect that this "more is better" heuristic would be used by individuals in judging the effectiveness of a company initiative to improve workplace diversity. This assumption is supported by research in the base-rate neglect literature, which indicates that people do not always attend to population base rates or incorporate such information when making judgments (e.g., Casscells, Schoenberger, \& Grayboys, 1978; Goodie \& Fantino, 1995, 1999; Medin \& Edelson, 1988). The U.S. Census data collected in 2000 indicates that the U.S. population is split rather evenly on gender (50.9\% female to $49.1 \%$ male), and is approximately $75 \%$ white, $12 \%$ Black or AfricanAmerican, and 13\% Hispanic (U.S. Census, 2000). This information should be useful to decision makers when forming judgments about whether a group of people is diverse. However, the base rate neglect literature indicates that knowledge of base rates does not necessarily improve the accuracy of people's judgments. The engineer-lawyer problem is a classic example of base rate neglect (Kahneman \& Tversky, 1973). Participants were asked to review five descriptions that had been randomly chosen from 30 engineer and 70 lawyer descriptions written by a panel of psychologists. Participants were asked to review and assess the probability that the person described was an engineer. The situation was also reversed for half of the participants so that the base rate was 70 engineers and 30 lawyers. Mean judgments in the high engineer group were only $5 \%$ higher than the low engineer group indicating that the participants largely ignored the base rates for group membership. Researchers have found evidence of base rate neglect in a number of domains (e.g., Casscells, Schoenberger, \& Grayboys, 1978; Goodie \& Fantino, 1995, 
1999; Medin \& Edelson, 1988) suggesting that it is common for people to ignore or underutilize this type of information when it is available.

There has been some speculation about the mechanisms that underlie base rate neglect. Kahneman and Tversky (1973) concluded in the engineer-lawyer problem that their participants relied on a representativeness heuristic in making their decision. The representativeness heuristic states that people judge the probability of an event based on its similarity to their prior concepts of that event. With the engineer-lawyer problem, the more similar the description was to the participant's ideal of an engineer, the more likely they were to state that the person was an engineer and the less likely they would incorporate base rate information into their decision making process. Similarly, perceptions about group diversity could be influenced by how representative the group appears to be to people's own conceptions of the distribution of diversity in the general population.

Consistent with a "more is better" heuristic is a preference for equality in social exchange. Equality in a diversity context could be achieved through the equal distribution of resources between the minority and non-minority groups. There is much research indicating that our judgments of fairness are heavily influenced by a preference for outcomes to be evenly distributed between all involved parties. Bazerman (1993) argued that people frequently engage in social comparison and are often guided by these comparisons in forming fairness judgments. Equality heuristics can also be influenced by the social environment (Leventhal, 1980). For example, organizations characterized with an economic-oriented culture may be more likely to utilize an equity rule that distributes resources to those who have used them effectively in the past (Deutsch, 1975). Alternatively, organizations with a relationship-oriented culture may 
prefer an equality distribution where resources are distributed equally among all members (Deutsch, 1985).

Research supporting equality preferences in organizations have often focused on the distribution of resources or awards among employees. For example, using MBA students, Mannix, Neale, and Northcraft (1995) had participants role-play a negotiation between divisionheads of a high tech firm who were to assign new projects to three departments. When the high tech firm was described as an economic-oriented culture (e.g., emphasized and rewarded economic productivity) the participants were more likely to use an equity rule when assigning the new projects to departments. In this case, participants would look at the past performance and future potential of each area and allocate work accordingly. In contrast, when the tech firm was described as being relationship-oriented (e.g., emphasized strong personal relationships and mutual respect), the participants used an equality rule and distributed the new projects equally among all departments.

Martin and Harder (1988) reported several case studies of how rewards are allocated in organizations and found that, depending on the type, rewards were allocated using different distributive rules but that equality principles influence reward allocation just as much as equity principles. Additionally, Meindl (1989), incorporating a similar methodology to Martin and Harder (1988), found that organizations used an equality rule when the solidarity among organization members was emphasized but used an equity rule when productivity was emphasized. They also found that when goals were incongruent (e.g., emphasizing both productivity and solidarity) managers relied on equality rather than equity to distribute resources (Meindl, 1989). These results indicate that equality principles are just as important within organizations as equity principles, and at some times may even be more important. 
Additional evidence of preference for equality within judgment and decision making tasks has found that this behavior can be irrational. An example of this type of irrational behavior can be defined through pareto efficiency. Pareto efficient agreements occur when no other agreement between two parties exists that would make one party better off without decreasing the outcomes of the other party (Bazerman, 1993). For example, choosing to receive $\$ 600$ for yourself and $\$ 800$ for your partner versus $\$ 500$ for each of you is a pareto efficient agreement because both you and your partner would be receiving the maximum amount of money. Choosing the $\$ 500$ option, where you would receive $\$ 100$ less at the gain of being equal with your partner, would be pareto inefficient behavior. Bazerman (1993) argues, however, that this is exactly what people do. In a series of research studies participants rated receiving $\$ 500$ for the self and $\$ 500$ for their partner as being a much more acceptable outcome than receiving $\$ 600$ for the self and $\$ 800$ for their partner (Loewenstein, Thompson, \& Bazerman, 1989).

The results of the Bazerman studies suggest that, when social comparison is at play our value for equality seems to outweigh our need to attain the maximum outcome from a situation. Because we value equality so highly, even when it is to our economic advantage not to, we may hesitate to rate a diversity management program as being successful until group membership has been evenly distributed between the minority and non-minority populations. In this circumstance, a group may only be judged as diverse when the minority group approximates $50 \%$ of group membership.

Based on these arguments, I would expect a main effect for amount of diversity on judgments about an organization's efforts at managing diversity. The base-rate neglect literature indicates that population base rates are not always incorporated into the decision making process (e.g., Casscells, Schoenberger, \& Grayboys, 1978; Goodie \& Fantino, 1995, 1999; Kahneman \& 
Tversky, 1973; Medin \& Edelson, 1988). I argue that participants will use an equality heuristic and will provide the strongest ratings when the minority population holds equal group membership as the non-minority population. Therefore, judgments about the effectiveness of diversity programs will increase non-linearly for judgments of race/ethnicity and gender diversity and will peak at $50 \%$.

H2: There will be a main effect of minority presence on judgments of the effectiveness of diversity efforts, such that people will give higher ratings of the organization's effort at managing diversity when the proportion of minorities in the group is equal to the proportion of non-minorities.

\section{Information Frames}

People's judgments of an organization's effort at managing diversity may also be shaped by how information about group membership is framed. For example, the outcomes of a diversity initiative to increase minority presence can be framed in terms of the number of minority (e.g., Black, Hispanic, female) or non-minority (e.g., White, male) people hired. Judgment and decision making literature is replete with examples of the effect that information frames can have on people's perceptions and opinions (Levin, Schneider, \& Gaeth, 1993). Decision frames, made popular by Tversky and Kahneman (1981), "are the conceptions that decision maker's carry about the acts, outcomes, or contingencies associated with a particular choice." These conceptions can be influenced by how a problem is formulated and also by the norms, habits, and characteristics of the decision maker (Tversky \& Kahneman, 1981). One of the more classic examples of framing is the "Asian disease" problem which is a type of risky choice framing (Levin, Schneider, \& Gaeth, 1993). In this problem, participants are told that an Asian disease is expected to kill 600 people. Participants are given two choices of programs to 
combat the disease, one option which involves more risk than the other. Tversky and Kahneman (1981) found that, when the programs were framed as the number of lives saved, a majority of the participants preferred the less risky option. When the programs were framed in terms of lives lost, however, preferences were reversed; the majority of participants instead preferred the riskier program. The central tenet behind risky choice framing is the emphasis on the potential gains or losses associated with the options (Levin et al., 1998). An additional type of framing that is applicable to the study of diversity perceptions is attribute framing.

Attribute Framing. Attribute framing is the simplest form of framing because only a single attribute is the subject of manipulation within a frame, allowing for a precise evaluation of how descriptive framing can influence information processing (Levin et al., 1998). In attribute framing, participants are not presented with the choice between two options, as in risky choice framing. Instead people are presented with information about an object or event in one form such as success versus failure, good versus bad, or acceptable versus unacceptable. For example, one of the more notable manipulations of attributes was a study of consumer preferences for ground beef. Levin and Gaeth (1988) found that when ground beef was described as "75\% lean" the ground beef was rated as tasting better and less greasy than if the ground beef was labeled as " $25 \%$ fat." Levin and colleagues argue that attribute framing works by producing a valenceconsistent shift in responses through the encoding and representation of information in associative memory (Levin et al., 1998). Levin and Gaeth (1988) reason that the positive labeling of attributes leads people to encode the attribute favorably in memory; conversely, negative labeling of attributes leads to unfavorable encoding in memory.

In diversity research, framing the outcome of a diversity management program in terms of the percentage of diversity in the group may produce a more favorable reaction than if the 
outcome is framed otherwise. Diversity management programs are designed to increase minority presence, therefore, a program that frames the outcomes of diversity management in terms of the amount of group diversity present may highlight the impact the program has had on the bottomline of diversity and yield different evaluations than if framed in terms of the amount of nondiversity. Levin and Gaeth (1988) argued that labeling ground beef as "75\% lean" was a more positive frame than labeling ground beef as " $25 \%$ fat" because the process of encoding the word "lean" in working memory evoked more favorable connotations in memory than the process for encoding the word "fat." Similarly, framing group diversity in terms of the percentage of diversity (versus non-diversity) in a group may connote different judgments about the effectiveness of a diversity management program because the minority population (e.g., Blacks and Hispanics, Women) would presumably evoke more favorable associations with diversity in memory than the non-minority population (e.g., Whites, Men).

There have been quite a few studies testing the effects of attribute framing in HRM functions. Davis and Bobko (1986) found that evaluations of a job placement program were higher when the outcome was framed as the "successful placement of $39.9 \%$ of participants" as opposed to when the outcome was described as "a failure to place $60.1 \%$ of participants." In an organizational context Dunegan (1993) explored the effect of attribute framing on budget allocation for special projects. Proposals from groups whose previous experience was framed as "20 of the last 50 projects have been unsuccessful" were rated as being more risky and participants indicated a higher concern for minimizing losses than if the group's previous experience was framed as "30 of the last 50 projects were successful" (Dunegan, 1993). Wong and Kwong (2005) found that, in a performance appraisal task, performance information framed positively through attendance, completeness, or accuracy rates yielded higher performance 
ratings than performance information framed negatively through absence rates, incompleteness, or error rates. These examples provide further support that attribute framing yields valenceconsistent shifts through the way that positive and negative attributes are encoded.

Similarly, framing group diversity in terms of the amount of diversity or non-diversity present in the group could also evoke a valence-consistent shift in responses as has been found in previous framing studies (e.g., Davis \& Bobko, 1986; Dunegan, 1993; Wong \& Kwong, 2005) because the minority population label would be encoded such that it is linked with more favorable associations of diversity than the non-minority population label. For example, describing a diversity program as being $40 \%$ women highlights the impact that the diversity initiative had in improving gender diversity than does framing the outcome in the non-minority population (e.g., $60 \%$ men). Describing group composition in terms of the proportion of diversity may evoke a stronger perception of diversity because it portrays the initiative in more positive terms. Additionally, the amount of diversity may be more psychologically meaningful when framed with the minority population because it highlights the gains made by a diversity initiative and the success it has achieved.

H3: Judgments about the effectiveness of diversity efforts will be more favorable when group composition is framed in terms of the proportion of the minority group than in terms of the proportion of the non-minority group.

\section{Overview of Present Study}

In the present study I empirically tested the effects of type of diversity, amount of diversity, and information frame on judgments about a diversity management program. This study sampled individuals using a between-subjects design. In this experiment, participants were asked to make judgments about the workforce diversity of an organization that varies in the type 
of diversity (i.e., race or gender), the amount of diversity (i.e., 3, 5, or 7, out of 10 people), and the information frame (i.e., minority or non-minority population). The levels 3,5 , and 7 out of 10 people were chosen in order to compare instances when the minority group held smaller group membership, equal group membership, and larger group membership than the nonminority group. Items were written that assessed people's perception of the definition of diversity and the organization's efforts at managing diversity. 


\section{METHOD}

\section{Participants}

Participants were recruited from the StudyResponse Project. The StudyResponse Project is a non-profit, academic service that matches researchers in need of samples with people willing to participate in surveys (Stanton \& Weiss, 2002). As of August 10, 2005, StudyResponse Project had approximately 95,000 people registered in their database. A random sample of 2,000 individuals was requested; StudyResponse recruited an additional 2,000 people to account for incorrect or expired email addresses. Correspondence with StudyResponse administrators indicated that only one of the 4,000 emails was returned as undeliverable. Approximately 466 individuals participated giving a response rate (out of 3,999$)$ of $12 \%$. This response rate is similar to other researchers who have used the StudyResponse panel (e.g., Piccolo \& Colquitt, 2006). Further data cleaning removed 14 individuals for taking less than 2 minutes to complete the survey (pre-testing indicated that it would take a person a minimum of 5 minutes to read and complete the study material for the current study and the second, unrelated study), 25 individuals for missing data, and 42 individuals who incorrectly answered a validity question from the second study. The final sample was 385 .

A summary of demographic information can be found in Table 1. Approximately $59 \%$ of the sample was female and $51 \%$ of the sample indicated they were residents of the United States. Seventy-two percent of the sample was white with the remaining participants identifying as African-American (4\%), Hispanic (2\%), Asian/Pacific Islander (15\%), Arabic or Middle-Eastern (1\%), or more than one race $(6 \%)$. Participants ranged in age from 18 to 66 with an average age of $39.60(S D=11.05)$. Most participants were employed full-time $(63 \%)$ and had worked an average of 18 years $(S D=11.64)$. This sample represented 33 different occupation types with 
the most common being Administrative Support (10\%), Education/Training (9\%), Health or Safety (7\%), Technology (7\%), or Accounting and Finance (6\%).

\section{Stimuli and Procedure}

Participants were contacted by a StudyResponse Project administrator with an invitation to participate in the study and the study hyperlink. After reading the informed consent, participants were randomly assigned into a study condition by indicating the month in which they were born.

Participants were informed that the purpose of the study was to determine their perceptions of an organization's effort to increase workforce diversity. The design of the experiment was a 2 (type; race versus gender) x 3 (amount; 3/10, 5/10, 7/10) x 2 (information frame; minority versus non-minority) factorial. Study conditions are included in the Appendix. Participants responded to the dependent variables and then completed a second, unrelated study before being asked to estimate the percentage of the U.S. population that is female and that is a racial minority. The study concluded with demographic questions and an opportunity for participants to enter their StudyResponse ID into a lottery to win one of eight $\$ 54$ gift cards to Amazon.com. Data collection took place during a two week time period. Reminder emails were sent to all non-respondents after one week.

\section{Dependent Variables}

Reactions to organization diversity were measured with seven items (Appendix) adapted from Guidroz and Highhouse (2005). Three items were developed to assess a participant's conception of diversity. For example, one item was "This is not what I think of when I think about workplace diversity." For ease of interpretation, the Conception of Diversity items were 
reverse-coded such that a high score indicates agreement that the workforce diversity represents the person's idea of diversity. Four items were written to asses the diversity management efforts of the organization. A sample item includes "Outsiders would view this company as diverse." Responses to all items were made on a five-point, Likert-type scale ranging from "strongly disagree" to "strongly agree." 


\section{RESULTS}

\section{Preliminary Analyses}

Exploratory factor analysis was conducted to confirm the presence of two, distinct dependent variables. Intercorrelation between some of the items was expected. Therefore, a principal axis factoring (PAF) with oblique rotation was used (Fabrigar, Wegener, MacCallum, $\&$ Strahan, 1999). PAF determines the least number of factors that can account for the common variance of the set of variables. Two distinct factors emerged accounting for $60 \%$ of the variance in diversity perceptions (see Table 2). Following Tabachnik and Fiddel's (2001) recommendation, .32 was used as the minimum loading for an item to be retained within the scale. All items clearly loaded on to one of the two factors and had communalities of . 39 or higher. Cronbach's alpha for the Conception of Diversity variable was .75 and was .69 for Diversity Management Efforts.

Second, approximately $40 \%$ of the sample indicated that they were not U.S. residents. Little previous research has explored cross-national differences in judgments of diversity. Additionally, what is considered a racial or ethnic minority in the U.S. may not be considered a minority in another country. To determine if residency status related to perceptions of diversity, t-tests were used to compare responses on the two dependent variables between U.S. and nonU.S. residents. Independent samples t-test indicated that U.S. and non-U.S. residents did not differ significantly on Conception of Diversity, $t(348)=.47, p=.637$, or Diversity Management Efforts, $t(348)=-1.03, p=.305$. 


\section{Hypothesis Testing}

Means, standard deviations, and intercorrelations between study variables can be found in Table 3. Significant correlations were found between Conception of Diversity and age ( $r=-.13$, $p<.01)$ and tenure $(r=-.19, p<.01)$. Diversity Management Efforts was also correlated with age $(r=-.12, p<.05)$. Tenure and age were very highly correlated $(r=.75, p<.01)$ making it unnecessary to include both variables as covariates. As such, age was controlled for during hypothesis testing. Gender and race were not correlated with Conception of Diversity (Race: $r=$ $.08, p>.10$; Gender: $r=-.09, p>.10$ ) or with Diversity Management Efforts (Race: $r=.01, p>$ .10 ; Gender: $r=-.08, p>.10$ ) but previous research indicates that participant race and gender should be controlled for in diversity research (e.g., Avery, 2003). Therefore, age, race, and gender were included as covariates in all hypothesis tests.

The first hypothesis stated that race/ethnic diversity will be perceived as contributing to diversity more than gender diversity. To test this hypothesis, a 2 (diversity type) x 3 (amount) $\mathrm{x}$ 2 (information frame) univariate analysis of covariance was run with Conception of Diversity as the dependent variable. After controlling for gender, race, and age, a significant main effect was found for diversity type $F(1,368)=15.25, p<.01, \eta^{2}=.04$ (Table 4$)$. An unexpected interaction was found for type of diversity by information frame on Conception of Diversity, $F$ $(1,368)=6.15, p<.01, \eta^{2}=.02$ suggesting that the effect of diversity type was more complex than hypothesized. Post-hoc analyses indicate that the effect of type only occurred when diversity was framed in terms of the proportion of racial minorities in the workforce, not when it was framed in terms of the proportion of Whites, women, or men (see Table 5 and Figure 1). Ratings given by participants in the "proportion of women" condition were not significantly different from ratings given in the "proportion of men" condition, $t(187)=.34, p>.10$. Nor 
were ratings given by participants in the "proportion of men" condition significantly different from ratings in the "proportion of White" condition, $t(177)=.72, p>.10$. Workforce diversity described in terms of the proportion of Black or Hispanic people in the workforce $(M=2.88 ; S D$ $=.89$ ) was rated as being more representative of diversity and was significantly higher than when the workforce was described in terms of the proportion of White people, $t(194)=3.32, p<.01, d$ $=.48$, the proportion of Men, $t(195)=4.16, p<.01, d=.60$, or the proportion of Women, $t(204)$ $=4.81, p<.01, d=.67$. This was found even though both conditions described exactly the same amount of diversity (e.g., $70 \%$ were women versus $30 \%$ were men).

For Hypothesis Two I reasoned that people would use an equality heuristic and judge an organization's efforts to manage diversity more favorably when the minority and non-minority groups held equal group membership, regardless of diversity type. Again, a 2 × 3 x 2 univariate analysis of covariance was run with Diversity Management Efforts as the dependent variable. After controlling for participant age, race and gender, a significant main effect was found for amount of diversity, $F(2,364)=8.59, p<.01, \eta^{2}=.05$ (see Table 6). Post hoc analyses indicate that an organization's efforts at managing diversity were rated significantly higher when the minority group was $50 \%$ of employees $(M=3.14, S D=.65)$ than when the minority group was $30 \%$ of employees, $(t(258)=3.57, p<.01 ; M=2.83, S D=.74 ; d=.44)$ or $70 \%$ of employees, $(t(252)=2.99, p<.01 ; M=2.88, S D=.74 ; d=.37)$. Planned comparisons were run to determine if a linear or quadratic trend best fit the pattern of means for amount of diversity. Results of the one-way ANOVA test can be found in Table 7. Test for a linear trend was not significant, $F(1,378)=.25, p>.10$, but the quadratic trend was significant, $F(1,378)=13.92$, $p<.01$ (see Figure 2). There is a main effect for amount of diversity on judgments about the 
organization's efforts such that efforts are rated highest when the organization has an equal number of minority and non-minority people in the workforce.

Hypothesis three proposed that judgments about the effectiveness of a diversity management program would be more favorable when group composition was framed in terms of the proportion of the minority group present than if framed in terms of the proportion of the nonminority group. Returning to the $2 \times 3 \times 2$ univariate analysis of covariance run to test Hypothesis 2 (see Table 6) a significant main effect was found for information frame, $F(1,364)$ $=6.70, p<.01, \eta^{2}=.02$. An unexpected interaction was found, however, for information frame by type of diversity, $F(1,364)=8.45, p<.01, \eta^{2}=.02$, indicating that the effect of information framing is more complex than anticipated. Similar to Hypothesis one, the effect of information framing only occurred in the Race/Ethnicity condition. Organizational efforts were rated highest when group diversity was described in terms of the proportion of Blacks or Hispanics in the workforce $(M=3.19 ; S D=.70)$ and were rated lowest when described in terms of the proportion of Whites in the workforce $(\mathrm{M}=2.78 ; S D=.72), t(192)=3.91, p<.01, d=.58$. Ratings given in the "proportion of women" conditions were not significantly different from ratings in the "proportion of men" conditions, $\mathrm{t}(185)=.89, p>.10$ nor were ratings in the "proportion of men" conditions significantly different from ratings given in the "proportion of White" conditions, $\mathrm{t}(176)=1.54, p>.10($ see Table 8 and Figure 3$)$.

To summarize, a significant effect was found for diversity type on Conception of Diversity but the interaction with information frame indicates that the effect only occurred when the population was framed in terms of the proportion of "Blacks and Hispanics" in the workforce. There was a main effect for amount of diversity in the hypothesized direction. Participants rated the organization's effort at managing workforce diversity highest when there 
was a balance between the minority and non-minority groups. Finally, similar to Hypothesis one, an effect of information frame was found on perceptions of Diversity Management Efforts but the interaction with diversity type indicated that the effect was only present when the workforce diversity was framed in terms of the proportion of "Blacks and Hispanics."

\section{Exploratory Analyses}

Although not hypothesized, analyses were run to explore participant's knowledge of population base-rates of women and racial/ethnic minorities in the United States. At the conclusion of the study, participants were asked to estimate what proportion of the U.S. population was female and what proportion was a racial or ethnic minority. For these analyses, only U.S. residents were included ${ }^{2}$. Z-tests were used to compare the sample mean to the population mean. Using estimates from the 2000 U.S. Census data, the population means were set to $50 \%$ for gender diversity and $25 \%$ for racial minority diversity (U.S. Census, 2000). Participants estimate of the proportion of the U.S. population that is female was 55\% ( $M=54.80$; $S D=9.61$, which is not that much higher than the U.S. Census estimate of $50 \%$, but the difference was significant, $z(191)=6.78, p<.01$. Participants also significantly over-estimated the proportion of the U.S. population that was a racial or ethnic minority, $M=43.33 ; S D=17.13$; $z(191)=14.83, p<.01$. If the U.S. population mean for racial minorities is raised to $33 \%$, (a recent reports estimates that as of $20061 / 3$ of the U.S. population is a racial minority; U.S. Census, 2007), this samples estimate is still significantly higher, $z(191)=8.36, p<.01$. Although the participant's estimates were higher than the U.S. Census, this statistical

\footnotetext{
2 Two separate ANCOVA's were conducted to rule out any effect of study condition on participant's population estimates. No effect was found for amount of diversity, $F(2,92)=.52, p>.10$, or information framing, $F(1,92)=$ $1.98, p>.10$, on estimates of women in the population or for amount of diversity, $F(2,82)=.85, p>.10$, or information framing, $F(1,82)=1.31, p>.10$, on estimates of racial/ethnic minorities in the population.
} 
significance does not necessarily mean that the overestimation is practically significant.

Considering the large standard deviations, it appears that knowledge of population base-rates are rough approximations of the actual population (see Table 9) ${ }^{3}$.

\footnotetext{
${ }^{3}$ The results of the exploratory analyses bring in to question the effect that participant's knowledge of population base-rates may have on people's interpretation of the amount of diversity. To rule out a potential confound, the analyses for Hypothesis two were re-run with population estimates of women and racial/ethnic minorities added as a covariate. The significance of amount of diversity on judgment of diversity efforts did not change (Table 10).
} 


\section{DISCUSSION}

This paper tested the effect of three contextual variables on people's judgments about workforce diversity and the efforts to manage diversity. Of the significant findings from this study, most notable are the differences observed in judgments between the conditions when workforce diversity was framed in terms of the proportion of "Blacks and Hispanics", as opposed to the proportion of "Women", "Whites", or "Men." When workforce diversity was described in terms of the proportion of "Blacks and Hispanics" participants rated this type of diversity as being most representative of their idea of diversity. Participants also perceived the organization as focusing more effort at managing diversity when the population was described as the proportion of "Blacks and Hispanics" than when diversity was framed in any other population (i.e., women, men, Whites). Additionally, participants demonstrated a preference for equality between the minority and non-minority groups; organizational scenarios where minorities and non-minorities held equal employment in the workforce were judged to be more successful at managing diversity than when one group held a numerical advantage over the other. These results offer implications for both the theory of workforce diversity and the practice of diversity management. I will discuss the results separately for each contextual variable included in this study.

\section{Type of Diversity}

Hypothesis one stated that racial diversity would be perceived as contributing to diversity more than gender diversity. This hypothesis was generally supported, however, the effect of type of diversity was more complex than expected due to interactions between type of diversity and information frame. Post-hoc analyses indicated that ratings of people's conception of 
diversity were significantly higher when workforce diversity was framed in terms of the proportion of "Blacks and Hispanics." There were no significant differences in people's conception of diversity when the population was described as the "proportion of Whites," "proportion of men," or "proportion of women" but these conditions were all significantly lower than when the population was described as the "proportion of Blacks and Hispanics."

The low ratings on Conception of Diversity given by participants in the "proportion of women" condition, specifically, are surprising and suggest that race and ethnicity may be more closely associated with people's idea of diversity than gender. Considered in context of other research, however, these results are not wholly inconsistent with public opinion. Recall the previously discussed Gallup Poll (2007) surveys from 2001 to 2006, which found that respondents were consistently more satisfied with how women are treated in society than with how Blacks or Hispanics are treated. One possible explanation for these results could be that the perceived barriers that women face in the workforce are not as great as those affecting racial/ethnic minorities and, consequently, women may not be seen as needing inclusion under the umbrella of diversity management. Additionally, women are increasingly representing a larger proportion of the U.S. labor pool. The United States Department of Labor's Bureau of Labor Statistics (2006) estimated that women made up 47\% of the U.S. workforce in 2006 while Blacks, Hispanics, and Asians combined to make up 29\% of the workforce. Considering the effect of amount of diversity in Hypothesis two, which showed a preference for equality in social exchange, if women already represent (almost) half of the U.S. workforce then the low ratings on the Conception of Diversity items by participants in the gender conditions could suggest that gender is not a demographic characteristic that needs to be a target of workforce diversity management efforts. However, an alternative explanation could also be that women and 
racial/ethnic minorities have different needs when it comes to placement in the workforce. Women are, arguably, more present in the U.S. workforce than Blacks or Hispanics, but, they are often employed at lower levels in the organization than men. Previous research on the "glass ceiling" of female advancement suggest that women often encounter more barriers to advancement than do men (Lyness \& Thompson, 1997; 2000). Study participants could have been responding to the lower representation of racial/ethnic minorities in the workplace in general as being a greater need than that of women. Had this study manipulated the level in the organization that the women were employed in or specified a gender-dominated industry the results might have been different.

These results have some implication for the theory of workforce diversity as well as for how diversity is portrayed in the workplace. As discussed previously, there is some division among diversity theories as to whether diversity should be conceptualized as a demographic characteristic or viewed more abstractly with a limitless number of choices (Hays-Thomas, 2004). The more recent theories of workforce diversity (e.g., Harrison \& Klein, 2007) have completely side-stepped the issue of demography and have solely focused on underlying traits, such as work values or functional background. But in light of the results of the present study, these theories might be better framed as theories of work group effectiveness rather than workforce diversity. Consider the following evidence. A previous study by Guidroz and Highhouse (2005) compared demography, in the form of race and gender, to a non-demographic type of diversity, functional background, and found similar results as the present study. When asked to rate the effectiveness of a diversity management program, university undergraduates rated the diversity initiative to be most effective when it contributed to the racial diversity of the organization. Second, in Soni’s (2000) survey of federal government employees nearly half of 
the sample endorsed the statement that "Diversity management is the current terminology for affirmative action" - a program long associated with race and ethnicity. Taken together, the present study, the results of Guidroz and Highhouse (2005) and Soni (2000), and the public opinion polls by Gallup (2007) add some merit to the idea that the American populace may place more value on race and ethnicity within the context of workforce diversity. Without the incorporation of race or ethnicity, academic theories of workforce diversity may be disconnected from the general public's perception and idea of diversity and, hence, may be limited in their application.

In terms of managing workforce diversity, these results are consistent with previous literature that has found that it is important to "look" diverse. As discussed previously, even the mere perception that a company is diverse can go a long way in attracting and recruiting minority applicants and appealing to minority consumers (Avery, 2003; Gilbert \& Stead, 1999; HaysThomas, 2004; Ng \& Burke, 2005). Recall Avery’s (2003) study in which Black participants were more attracted to organizations whose recruitment advertisements portrayed a Black employee in a supervisory role. If an organization wants to be perceived as being diverse then more emphasis should be placed on the racial/ethnic make-up of their employees. For example, when Starbucks Coffee Company is updating their Corporate Social Responsibility pamphlet, emphasizing the number of Blacks or Hispanics present on their board of directors and executive team may have more of an impact on people's judgments about Starbucks.

\section{Amount of Diversity}

Harrison and Klein (2007) argued that one limitation of previous diversity theories is that they did not move beyond identifying within-person differences and needed to determine the "distribution, shape, and meaning of maximal diversity (p. 3)." This study was designed in an 
attempt to address some of the shortcomings of previous diversity research. Study participants demonstrated a preference for equality when judging the effectiveness of the organization's diversity management effort. If taking the perspective that employment in a company is a resource that should be available to all people, then the results of the second hypothesis are consistent with previous judgment and decision making and organizational research that has found evidence of an equality preference in social exchange (e.g., Bazerman, 1993; Loewenstein, et al., 1989; Mannix et al., 1995; Martin \& Harder, 1988; Meindl, 1988). Additionally, there is precedence for this pattern of judgment in previous research on organizational attraction. As discussed earlier, Avery (2003) found that Black participants were most attracted to an organization when their recruitment brochure depicted a balance between Black and White employees, but only when a Black employee was depicted in a supervisory position. This suggests that a balance between both groups may be what is minimally expected by Black job seekers but what may tip the scale in one organization's favor is having Black people employed in higher levels of the organization.

The effect that amount of diversity had on judgments of the organization's efforts to manage diversity offer some insight into what maximal diversity would look like. In their typology Harrison and Klein (2007) state that maximal diversity will look different within a group depending upon if the diversity is an example of variety, separation, or disparity. The organization's efforts were rated highest by study participants when workforce diversity was split evenly between the minority and non-minority group for both types of diversity. Given that there are only two levels of each type of diversity examined in this study (e.g., male versus female, white versus non-white) it is difficult to determine if race and gender fall more clearly into the variety or separation category. For example, maximum separation is achieved when 
group members are polarized on an attribute such that half are very high and half are very low, and maximum variety could be achieved when there is a group member to represent each category or unit of an attribute. With only two levels of an attribute, maximum variety and separation would look the same. Future research could explore this very easily by not grouping all racial/ethnic minorities into a "minority" category and instead treating all possible racial/ethnic groups as distinct categories. These results do suggest, however, that maximum diversity should include both balance and equality, at a minimum, between all groups.

The non-significant interaction between type and amount of diversity provides an interesting observation on participant's judgments of population base-rates. If people were attuned to the population base-rates of racial and ethnic minorities in the United States then one would have expected ratings in the $30 \%$ minority condition to be higher than the $50 \%$ minority condition for race and ethnicity. But participants in the $30 \%$ condition actually gave the organization the lowest ratings on diversity management effort, across both types of diversity. There are several possible explanations for this outcome. Participants could simply have been unaware of population base-rates at the time they made their ratings and defaulted to an equality heuristic. However, participants did demonstrate knowledge of population base-rates later in the study (although the participant's estimates were slightly higher than what is believed to be the population base-rate); an alternative conclusion could be that participants were aware of the population base-rates but chose not to incorporate that knowledge when passing judgment on the organization's efforts at managing diversity.

Additionally, the non-significant interaction between amount of diversity and information frame is also interesting. One could have argued that participants would rate the $70 \%$ minority conditions higher than the $30 \%$ or $50 \%$ minority conditions because it would have showed the 
most effort on the part of the organization at increasing diversity. However, 70\% minority and $30 \%$ non-minority were given similar ratings. It could be that people's preference for equality carried more weight when judging the organization's effort than maximizing the presence of the minority group within the workforce. Alternatively, if, for example, $70 \%$ of the workforce is from any one racial group then that reduces the total amount of diversity that can be present in the workforce, regardless of if that $70 \%$ represents the minority (e.g., Blacks or Hispanics) or non-minority (e.g., Whites) population.

The effect of amount of diversity on judgments of the organization's effort, although informative, is problematic in terms of implementation. In some situations, this preference for equality could be achievable, particularly when the diversity in question is gender, but this rule may not apply for all types of diversity. When gender is the diversity target, it would be expected that a group representative of gender would be split 50/50 — and this group composition could be easily achieved given the population. However, approximately $75 \%$ of the U.S. population has self-identified as white, $12 \%$ as Black or African-American, and 13\% as Hispanic (U.S. Census, 2000). Although the ideals of equality would be served if a group of people were $50 \%$ white and 50\% Black and Hispanic or at best consisted of 1/3 of each race and ethnic group, this preference would violate economic models of supply and demand. There are not enough Black and Hispanic people in the population to create a group comparable in size to whites in race and ethnicity. Holding to our values of equality would increase the burden of creating a racially and ethnically diverse workforce. In employee selection, for example, having a group of new hires equally represent each major racial/ethnic group in the population would result in an overabundance of White applicants who are not hired, requiring extra effort instead to recruit people from the minority groups. Because our value for equality is so strong, we may still prefer 
a 50/50 split between the minority and non-minority population even though that ideal could not be achieved based on the availability within the working population.

\section{Information Frame}

This study provides an additional instance of how attribute framing can influence people's judgments of HRM practices (e.g., David \& Bobko, 1986; Dunegan, 1993; Wong \& Kwong, 2005). Previous research has found valence-consistent shifts when describing HRM practices through frames such as "attendance" versus "absence", "successful” versus "unsuccessful" or "successful placement" versus "failure to place." These shifts are thought to occur through a process of positive and negative encoding of the words in memory (Levin \& Gaeth, 1988). This is the first study to demonstrate a valence-consistent shift when using words that are less explicitly value-laden as other word combinations used in judgment and decision making research. However, results of the interaction of framing with diversity type indicated that framing only affected judgments of the organization's efforts in the race and ethnicity conditions. Framing gender diversity in terms of the proportion of women did not produce a valence-consistent shift and ratings in the "women" condition were not significantly different than the ratings in the "men" condition. Similar to the interaction found between diversity type and information framing on Conception of Diversity, participants perceived the organization as focusing more effort on managing diversity when diversity was described as the proportion of "Blacks and Hispanics" present in the workforce.

Although the effect of information framing on judgments of the organization's diversity management efforts provide further support to the idea that race and ethnicity are closely associated with the idea of diversity, the lack of an effect of attribute framing in the gender condition is, again, surprising, but consistent with the results of the first hypothesis. Results of 
the framing effect, thus, raise two questions: (1) why would an information frame effect be observed in the "race/ethnicity" conditions but not in the "gender" conditions and (2) what do the results suggest about how gender diversity is perceived by people? In regard to attribute framing, Levin et al. (1998) reasoned that the positive labeling of attributes leads people to encode the attribute more favorably in memory which results in a more positive rating for that attribute. In forming this hypothesis the same reasoning was applied such that attribute framing would evoke a stronger perception of diversity because it would portray the initiative in more positive terms and highlight the gains made by that initiative. This reasoning appears to be substantiated by the results and lends support to the conclusion that the "proportion of Blacks and Hispanics" attribute frame was encoded more favorably in memory by study participants than was the "proportion of Whites" frame. Thus, "Black and Hispanic" is more favorably viewed within the situational context of workforce diversity than is "White."

What this implies about gender diversity is a little less clear because this line of reasoning also suggests that the attribute frame "women" is not positively encoded within the context of workforce diversity. As discussed previously, the public opinion surveys by Gallup (2007) revealed that people believe women are treated much better in society than are Blacks or Hispanics. Also, considering that women make up a larger percentage of the U.S. workforce than racial minorities (Bureau of Labor Statistics, 2006), the result that "women" was not positively encoded in the same way as "Black and Hispanic" provides additional support to the idea that gender may not be what people have in mind when they think of diversity or what they expect to see when a company talks about their diversity management efforts. 


\section{Limitations and Future Research}

There are several limitations to this study that provide insights into future research. This study only included two types of demographic diversity. Including other types of diversity, especially non-demographic types of diversity, would provide insight into whether and how people differentiate between underlying and visible types of diversity. Moreover, future research should include other types of demographic diversity in order to expand the inferences from this study to other types of demographic diversity that are often protected in the workplace, such as age or physical disabilities. Another area of future research would be to evaluate the conjunctive effect of multiple types of diversity. Race and ethnic diversity elicited the strongest ratings from this sample, which provides interesting follow-up questions. How would an organization diverse in race/ethnicity compare to an organization diverse in race/ethnicity and gender? Similarly, are there some racial/ethnic groups that hold more diversity "value" than others? A policy capturing study would be an ideal methodology for obtaining this sort of information.

Future research should also further explore base-rate neglect in workforce diversity. The design of this study was not sufficient to fully test for base-rate neglect because participants were not informed of the base-rate during the study. Participant's did demonstrate knowledge of the population base-rates and the main effect for amount of diversity do provide some initial evidence that study participant's ignored or did not attune to population base-rates when making judgments about the organization. A second study would be needed to explicitly test for baserate neglect.

In regard to attribute framing, the unobserved valence-consistent shift in the gender conditions is surprising and the reasons for this are not entirely clear. One conclusion that can be drawn is that this sample of participants does not view gender diversity as being 
underrepresented in the general workforce. The stimulus materials described the organization in very general terms and did not provide any contextual information about the service provided, industry, or marketplace. A potential follow-up study could explore the boundary conditions of gender diversity by describing the organization as being in a male-dominated industry, such as manufacturing or engineering, or varying the proportion of women in upper management.

\section{Conclusions}

In summary, this study tested the effects of type of diversity, amount of diversity, and information frame on judgments about the outcomes of a workforce diversity program. Study results suggest that people respond better to information about diversity management programs when framed in terms of the minority population, particularly when the diversity target is race or ethnicity. Balance between the minority and non-minority populations produced the highest judgments about an organizations effort at managing diversity and suggest that participants may use an equality heuristic when judging how effective an organization is at managing diversity. Future research should be directed toward exploring the boundary conditions of gender diversity and identifying other contextual variables that may contribute to an organization's perceived effort at improving gender diversity. 


\section{REFERENCES}

3M et al. (2003). Brief for amici curiae 65 leading American business in support of respondents Retrieved March 15, 2005, from University of Michigan Admissions Lawsuits, website: http://www.umich.edu/ urel/admissions/.

Avery, D. R. (2003). Reactions to diversity in recruitment advertising—are differences black and white? Journal of Applied Psychology, 88, 672-679.

Bantel, K. \& Jackson, S. (1989). Top management and innovations in banking: Does the composition of the team make a difference? Strategic Management Journal, 10, 107-124.

Bazerman, M. H. (1993). Fairness, social comparison, and irrationality. In ... pp. 184-203.

Blau, P. (1977). Inequality and heterogeneity: A primitive theory of social structure. New York: Free Press.

Bowers, C., Pharmer, J. A., \& Salas, E. (2000). When member homogeneity is needed in work teams: A meta-analysis. Small Group Research, 31, 305-327.

Bowl, K. (2001). Diversity means good business, survey says. HRNews, 46, 12.

Casscells, W., Schoenberger, A., \& Grayboys, T. (1978). Interpretation by physicians of clinical laboratory results. New England Journal of Medicine, 299, 999-1000.

Cohen, J. (1992). A power primer. Psychological Bulletin, 112, 155-159.

Costello, A. B., \& Osborne, J. W. (2005). Best practices in exploratory factor analysis: Four recommendations for getting the most from your analysis. Practical Assessment, Research, \& Evaluation, 10(7). 
Cox, T. H. (1997). Linkages between managing diversity and organizational performance. In T. R. Cox, Jr. and R. L. Beale (eds.), Developing competency to manage diversity (pp. 3542). San Francisco, CA: Jossey-Bass.

Cox, T. H., \& Blake, S. (1991). Managing cultural diversity: Implications for organizational competitiveness. Academy of Management Executive, 5, 45-57.

Cummings, J. N. (2004). Work groups, structural diversity, and knowledge sharing in a global organization. Management Science, 50, 352-364.

Dahlin, K. B., Weingart, L. R., \& Hinds, P. J. (2005). Team diversity and information use. Academy of Management Journal, 48, 1107-1123.

Davis, M. A., \& Bobko, P. (1986). Contextual effects on escalation processes in public sector decision making. Organizational Behavior and Human Decision Processes, 37, 121-138.

Deutsch, M. (1975). Equity, equality, and need: What determines which value will be used as the basis of distributive justice. Journal of Social Issues, 31, 137-149.

Deutsch, M. (1985). Distributive justice: A social psychological perspective. New Have, CT: Yale University Press.

Dunegan, K. J. (1993). Framing, cognitive modes, and image theory: toward an understanding of a glass half full. Journal of Applied Psychology, 78, 491-503.

Ely, R. J. (2004). A field study of group diversity, participation in diversity education programs, and performance. Journal of Organizational Behavior, 25, 755-780.

Ely, R. J. \& Thomas, D. A. (2001). Cultural diversity at work: The effects of diversity perspectives on work group processes and outcomes. Administrative Science Quarterly, 46, 229-273. 
Fabrigar, L. R., Wegener, D. T., MacCallum, R. C., \& Strahan, E. J. (1999). Evaluating the use of exploratory factor analysis in psychological research. Psychological Methods, 4, 272299.

Gallup (2007). The Gallup Poll: Race Relations. Retrieved on March 25, 2007 from The Galup Poll website: http://www.galluppoll.com.

General Motors (2003). Brief of General Motors Corporation as amicus curiae in support of respondents. Retrieved on March 15, 2005, from University of Michigan Admissions Lawsuits, website: http://www.umich.edu/ urel/admissions/.

Gillham B. (2000) Developing a Questionnaire. Continuum, London.

Gilbert, J. A., \& Stead, B. A. (1999). Does diversity management make a difference in applicant success? Group \& Organization Management, 24, 239-256.

Gini, Corrado (1921). "Measurement of Inequality and Incomes". The Economic Journal 31: 124-126.

Gratz v. Bollinger, (2003)

Goodie, A. S. \& Fantino, E. (1995). An experientially derived base-rate error in humans. Psychological Science, 6, 101-106.

Goodie, A. S. \& Fantino, E. (1999). What does and does not alleviate base-rate neglect under direct experience. Journal of Behavioral Decision Making, 12, 307-335.

Guidroz, A.M. \& Highhouse, S. (2005, November). What is diversity? Exploring type, amount, and format. Poster presented at the annual meeting of the Society for Judgment and Decision Making, Toronto, ON, Canada. 
Harrison, D. A., \& Klein, K. J. (2007, Forthcoming). What's the difference? Diversity constructs as separation, variety, or disparity in organizations. Academy of Management Review.

Harrison, D.A., Price, K.H., \& Bell, M.P. (1998). Beyond relational demography: Time and the effects of surface- and deep-level diversity on work group cohesion. Academy of Management Journal, 41, 96-107.

Hays-Thomas, R. (2004). Why now? The contemporary focus on managing diversity. In M. S. Stockdale and F. J. Crosby (Eds.), The psychology and management of workplace diversity (pp. 3 - 30). Massachusetts: Blackwell Publishing.

Jackson, S. E., Joshi, A., \& Erhardt, N. L. (2003). Recent research on team and organizational diversity: SWOT analysis and implications. Journal of Management, 29, 801-830.

Jackson, S. E., May, K. E., \& Whitney, K. (1995). Understanding the dynamics of diversity in decision-making teams. In R. A. Guzzo, E. Salas, and Associates (eds.), Team effectiveness and decision making in organizations (pp. 204-261). San Francisco, CA: Jossey-Bass.

Kahneman, D., \& Tversky, A. (1973). On the psychology of prediction. Psychological Review, $80,237-251$.

Kochan, T., Bezrukova, K., Ely, R., Jackson, S., Joshi, A., Jehn, K., Leonard, J., Levine, D., \& Thomas, D. (2003). The effects of diversity on business performance: Report of the diversity research network. Human Resource Management, 42, 3-21.

Lau, D. C. \& Murnighan, J. K. (1998). Demographic diversity and faultlines: The compositional dynamics of organizational groups. Academy of Management Review, 23, 325-340. 
Lau, D. C. \& Murnighan, J. K. (2005). Interactions within groups and subgroups: The effects of demographic faultlines. Academy of Management Journal, 48, 645-659.

Lee, C. \& Farh, J. L. (2004). Joint effects of group efficacy and gender diversity on group cohesion and performance. Applied Psychology: An International Review, 53, 136-154.

Leventhal, G. S. (1980). What should be done with equity theory? In K. Gergen, M. Greenberg, \& R. Willis (Eds.), Advances in experimental social psychology, New York: Academic Press.

Levin, I. P., \& Gaeth, G. J. (1988). Framing of attribute information before and after consuming the product. Journal of Consumer Research, 15, 374-378.

Levin, I. P., Gaeth, G. J., Schreiber, J., \& Lauriola, M. (2002). A new look at framing size effects: Distribution of effect sizes, individual differences, and independence of types of effects. Organizational Behavior and Human Decision Processes, 88, 411-429.

Levin, I. P., Schneider, S. L. \& Gaeth, G. J. (1998). All frames are not created equal: A typology and critical analysis of framing effects. Organizational Behavior and Human Decision Processes. 76, 149-188.

Loewenstein, G., Thompson, L., \& Bazerman, M. H. (1989). Social utility and decision making in interpersonal contexts. Journal of Personality and Social Psychology, 57, 426-441.

Lyness, K. S. \& Thompson, D. E. (1997). Above the glass ceiling? A comparison of matched samples of female and male executives. Journal of Applied Psychology, 82, 359-375.

Lyness, K. S. \& Thompson, D. E. (2000). Climbing the corporate ladder: Do female and male executives follow the same route?. Journal of Applied Psychology, 85, 86-101.

McLeod, P. L., Lobel, S. A., \& Cox, T., Jr. (1996). Ethnic diversity and creativity in small groups. Small Group Research, 27, 248-264. 
Mannix, E. A., Neale, M. A., \& Northcraft, G. B. (1995). Equity, equality, or need? The effects of organizational culture on the allocation of benefits and burdens. Organizational Behavior and Human Decision Processes, 63, 276-286.

Martin, J., \& Harder, J. (1988). Bread and roses: Justice and the distribution of financial and socio-emotional rewards in organizations. Research paper 1010. Stanford University Graduate School of Business, Stanford, CA.

Media Companies (2003). Brief of amici curiae media companies in support of respondents. Retrieved on March 15, 2005, from University of Michigan Admissions Lawsuits, website: http://www.umich.edu/ urel/admissions/.

Medin, D. L., \& Edelson, S. M. (1988). Problem structure and the use of base-rate information from experience. Journal of Experimental Psychology: General, 117, 63-85.

Meindl, J. R. (1989). Managing to be fair: An exploration of values, motives, and leadership. Administrative Science Quarterly, 34, 252-276.

Milliken, F. \& Martins, L. (1996). Searching for common threads: Understanding the multiple effects of diversity in organizational groups. Academy of Management Review, 21, 402433.

MTV Networks (2003). Motion for leave to file brief amicus curiae out of time and brief of MTV Networks in support of respondents. Retrieved on March 15, 2005, from University of Michigan Admissions Lawsuits, website: http://www.umich.edu/ urel/admissions/. 
Ng, E. S. W., \& Burke, R. J. (2005). Person-organization fit and the war for talent: Does diversity management make a difference? International Journal of Human Resource Management, 16, 1195-1210.

Pelled, L. H. (1996). Demographic diversity, conflict, and work group outcomes: An intervening process theory. Organizational Science, 7, $615-631$.

Piccolo, R. F. \& Colquitt, J. A. (2006). Transformational leadership and job behaviors: The mediating role of core job characteristics. Academy of Management Journal, 49, $327-$ 340.

Regents of the University of California v. Bakke, (1978)

Schwartz, D.J. (1996). The equal employment opportunity commission and other government agencies. In R. S. Barrett (ed.) Fair Employment Strategies in Human Resource Management. Quorum Books: Westport, CT.

Soni, V. (2000). A twenty-first-century reception for diversity in the public sector: A case study. Public Administration Review, 60, 395-408.

Stanton, J. M., \& Weiss, E. M. 2002. Online panels for social science research: An introduction to the StudyResponse project (Technical report no. 13001; www.studyresponse.com). Syracuse, NY: Syracuse University School of Information Studies.

Starbucks Coffee Company (2005). Beyond the cup: Highlights of Starbucks corporate social responsibility. Retrieved on March 15, 2006 from Starbucks Coffee Company website: http://www.starbucks.com/csr.

Tabachnick, B. G., \& Fidell, L. S. (2001). Using multivariate statistics ( $^{\text {th }}$ ed.). Boston, MA: Allyn \& Bacon. 
Tajfel, H., \& Turner, J. C. (1986). The social identity theory of intergroup behavior. In S. Worchel \& W. G. Austin (Eds.), Psychology of intergroup relations (pp. 7 - 24). Chicago: Nelson-Hall Publishers.

Turner, J. C. (1987). Rediscovering the social group: A self-categorization theory. Oxford, UK: Basil Blackwell.

Tversky, A., \& Kahneman, D. (1981). The framing of decision and the psychology of choice. Science, 211, 453-458.

U.S. Census (2000). Profiles of General Demographic Characteristics. Retrieved on July 7 , 2006, (www.census.gov).

U.S. Census (2007). Population Estimates. Retrieved on September 23, 2007, (www.census.gov).

U.S. Department of Labor Bureau of Labor Statistics (2008). Women's Bureau: Statistics \& Data. Retrieved on January 18, 2008. (www.dol.gov/wb/stats).

Webber, S. S., \& Donahue, L. M. (2001). Impact of highly and less job-related diversity on work group cohesion and performance: A meta-analysis. Journal of Management, 27, 141162.

Williams, K. Y. \& O’Reilly, C. A. (1998). Demography in diversity in organizations: A review of 40 years of research. Research in Organizational Behavior, 20, 77-140.

Wong, K. F. E. \& Kwong, J. Y. Y. (2005). Between-individual comparisons in performance evaluation: A perspective from prospect theory. Journal of Applied Psychology, 90, 284294. 


\section{APPENDIX: STUDY MATERIALS}

\section{Page 1 \\ BGSU。 \\ BOWLING GREEN STATE UNIVERSITY \\ Department of Psychology}

This survey is part of a dissertation being conducted at Bowling Green State University (BGSU). By completing this survey you have an opportunity to contribute to research regarding group and organizational processes. The results of this survey will be used to help researchers at Bowling Green State University understand people's reactions to outcomes of employee selection policies. Please remember that individuals must be at least 18 years old to participate in this study.

You will be participating in two separate studies. Completing both of them will take no more than 20 minutes. In appreciation of your participation, you will be entered into a lottery by the Study Response Project to win a \$54 gift certificate to Amazon.com. Approximately eight (8) gift cards will be given away. Only members of the research team, which include Dr. Scott Highhouse and graduate students Ashley Guidroz, Dalia Diab, Shuang-Yueh Pui, and Maya Yankelevich will have access to the information you provide.

Your participation in this study is voluntary. There are no adverse consequences should you decide not to participate. Completing this survey over the Internet implies consent. Those who do not want to participate may exit the survey at any time, without penalty. You have the right to refuse to answer any or all of the survey questions. The anticipated risks are no greater than those normally encountered in daily life. There may be no direct benefit to you, aside from the possibility of winning the gift certificate in the participant lottery. However, this research will inform those creating selection and admissions systems.

If you have any questions about this survey, you can contact Dr. Scott Highhouse. His phone number is (419) $372-$ 8078 and his e-mail address is shighho@bgsu.edu. Alternatively, you may also contact Ashley M. Guidroz in the psychology department at (419) 372-8238 or aguidro@bgsu.edu. If you have any questions about this study or your rights as a research participant, you may contact the Chair of Bowling Green State University's Human Subjects Review Board at (419) 372-7716 or hsrb@ bgsu.edu.

Thank you for your time!

Ashley M. Guidroz, M.A.

Department of Psychology

Scott Highhouse, Ph.D.

Department of Psychology

By clicking the "Next" button you are providing your consent to participate in this study.

HSRB \# for Study 1: H07D324GX2. Effective: 7-16-2007 Expires: 7-05-2008

HSRB \# for Study 2: H07P113FE7. Effective: 7-11-2007 Expires: 11-15-2007 


\section{Page 2}

\section{Q1 Study 1}

What month were you born in?

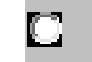

C

C

C

C

D June

E July

C August

C September

C October

C November

D December 


\section{Page 3}

We are interested in your perceptions of the effectiveness of diversity management programs. Following is a description of the outcome of one organization's effort to increase workforce diversity. Please read the description below and answer the questions on the next page.

Condition 1:

ABC Company initiated a program to increase workforce diversity. As a result, on average 3 out of 10 people in the company are women.

We are interested in your perceptions of the effectiveness of diversity management programs. Following is a description of the outcome of one organization's effort to increase workforce diversity. Please read the description below and answer the questions on the next page.

Condition 2:

ABC Company initiated a program to increase workforce diversity. As a result, on average 5 out of 10 people in the company are women.

We are interested in your perceptions of the effectiveness of diversity management programs. Following is a description of the outcome of one organization's effort to increase workforce diversity. Please read the description below and answer the questions on the next page.

Condition 3:

ABC Company initiated a program to increase workforce diversity. As a result, on average 7 out of 10 people in the company are women.

We are interested in your perceptions of the effectiveness of diversity management programs. Following is a description of the outcome of one organization's effort to increase workforce diversity. Please read the description below and answer the questions on the next page.

Condition 4:

ABC Company initiated a program to increase workforce diversity. As a result, on average only 3 out of 10 people in the company are men.

We are interested in your perceptions of the effectiveness of diversity management programs. Following is a description of the outcome of one organization's effort to increase workforce diversity. Please read the description below and answer the questions on the next page. Condition 5:

$A B C$ Company initiated a program to increase workforce diversity. As a result, on average only 5 out of 10 people in the company are men. 
We are interested in your perceptions of the effectiveness of diversity management programs. Following is a description of the outcome of one organization's effort to increase workforce diversity. Please read the description below and answer the questions on the next page.

Condition 6:

ABC Company initiated a program to increase workforce diversity. As a result, on average only 7 out of 10 people in the company are men.

\section{Please indicate your level of agreement with the following statements in response to the description you read on the previous page.}

Q2

\begin{tabular}{|c|c|c|}
\hline $\begin{array}{l}\text { Strongly } \\
\text { Disagree }\end{array}$ & Disagree & $\begin{array}{l}\text { Neither } \\
\text { Agree nor }\end{array}$ \\
\hline
\end{tabular}

This is not really diversity.
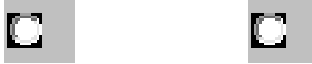

Disagree

This is not what I think of when I think about workplace diversity.
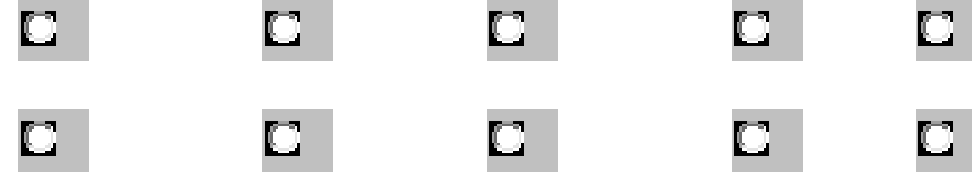

I think people mean something else when they use the word "diversity".
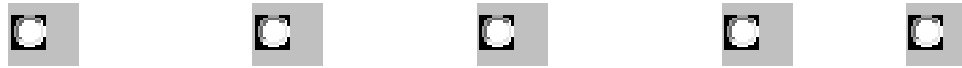

The company's efforts to increase gender diversity have been successful.
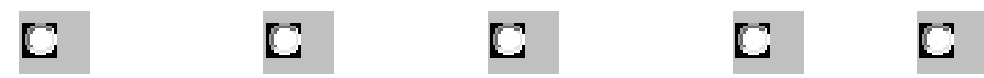

Outsiders would view this company as diverse.
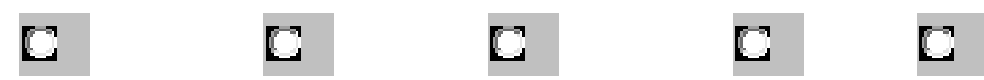

I think this company should make more effort to increase gender diversity.
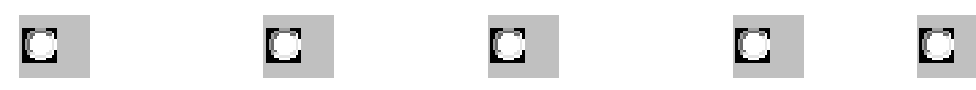

This company has achieved an optimal level of gender diversity.
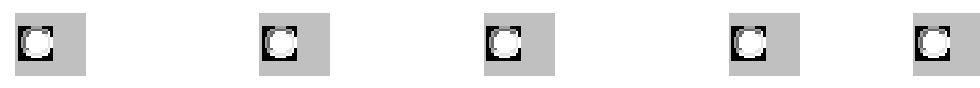

Q3

If you could set the optimal amount of gender diversity (out of 10) in the workforce what would it be? 
We are interested in your perceptions of the effectiveness of diversity management programs. Following is a description of the outcome of one organization's effort to increase workforce diversity. Please read the description below and answer the questions on the next page.

Condition 7:

ABC Company initiated a program to increase workforce diversity. As a result, on average 3 out of 10 people in the company are members of a racial minority group (e.g., Black, Hispanic).

We are interested in your perceptions of the effectiveness of diversity management programs. Following is a description of the outcome of one organization's effort to increase workforce diversity. Please read the description below and answer the questions on the next page.

Condition 8:

ABC Company initiated a program to increase workforce diversity. As a result, on average 5 out of 10 people in the company are members of a racial minority group (e.g., Black, Hispanic).

We are interested in your perceptions of the effectiveness of diversity management programs. Following is a description of the outcome of one organization's effort to increase workforce diversity. Please read the description below and answer the questions on the next page.

Condition 9:

ABC Company initiated a program to increase workforce diversity. As a result, on average 7 out of 10 people in the company are members of a racial minority group (e.g., Black, Hispanic).

We are interested in your perceptions of the effectiveness of diversity management programs. Following is a description of the outcome of one organization's effort to increase workforce diversity. Please read the description below and answer the questions on the next page.

Condition 10:

ABC Company initiated a program to increase workforce diversity. As a result, on average only 3 out of 10 people in the company are white (i.e., caucasian).

We are interested in your perceptions of the effectiveness of diversity management programs. Following is a description of the outcome of one organization's effort to increase workforce diversity. Please read the description below and answer the questions on the next page.

Condition 11:

ABC Company initiated a program to increase workforce diversity. As a result, on average only 5 out of 10 people in the company are white (i.e., caucasian). 
We are interested in your perceptions of the effectiveness of diversity management programs. Following is a description of the outcome of one organization's effort to increase workforce diversity. Please read the description below and answer the questions on the next page.

\section{Condition 12:}

ABC Company initiated a program to increase workforce diversity. As a result, on average only $\mathbf{7}$ out of $\mathbf{1 0}$ people in the company are white (i.e., caucasian).

\section{Please indicate your level of agreement with the following statements in response to the description you read on the previous page.}

\section{Q4}

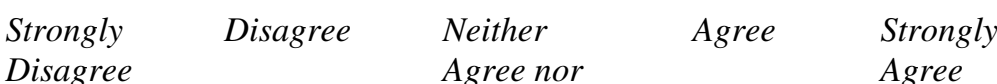

This is not really diversity.
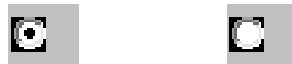

Disagree
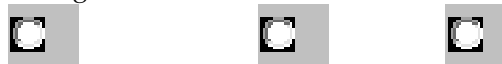

This is not what I think of when I think about workplace diversity.
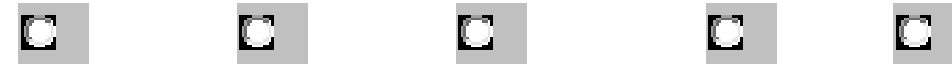

I think people mean something else when they use the word "diversity".
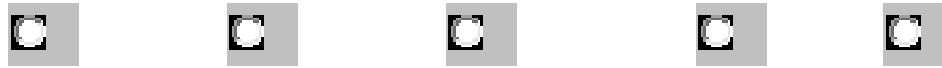

The company's efforts to increase race/ethnic diversity have been
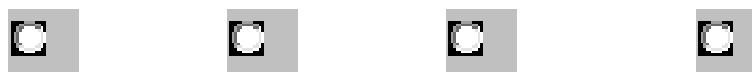

G successful.

Outsiders would view this company as diverse.
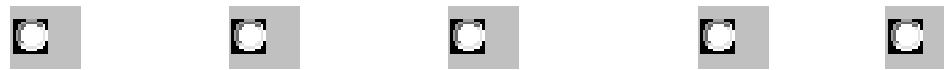

I think this company should make more
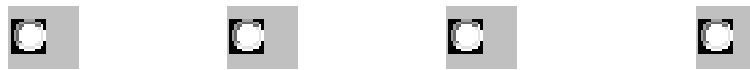

B

This company has achieved an optimal level of race/ethnic diversity.
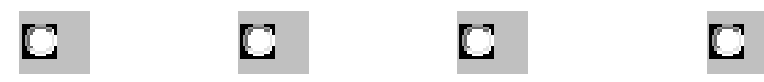

G

\section{Q5}

If you could set the optimal amount of race/ethnic diversity (out of 10) in the workforce what would it be? 


\section{Page 4}

\section{Study 2 Completed Next...}

\section{Page 5}

\section{Demographics}

Q19 On average, what percentage of the U.S. population is female?

Q20 On average, what percentage of the U.S. population is a racial or ethnic minority?

Q21 If you would like to be entered into a lottery to win one of eight \$54 gift certificates to Amazon.com please enter your Study Response Project ID\# here:

Q22 Age

Q23 Gender $\quad$ Male $\quad$ C $\quad$ Female

Q24 Race

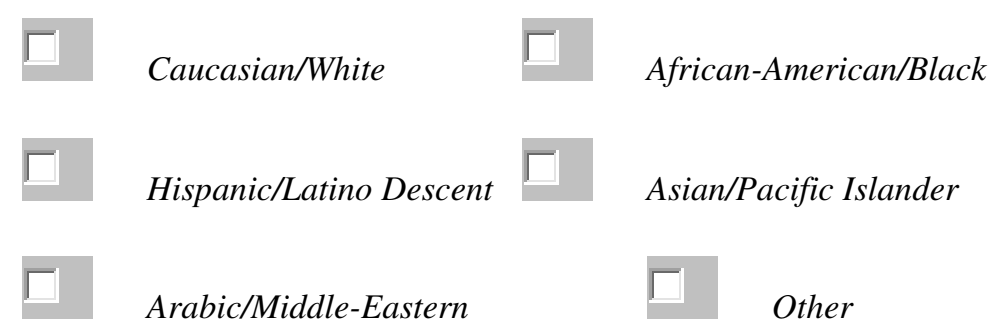

Q25 What industry are you employed in?

Q26 How many years total have you worked?

Q27 Zip code of your residence (for descriptive purposes only):

\section{Page 6}

Thank you for participating in our study! We appreciate you taking the time to complete it. If you have any further questions about this research please contact the researchers at:

Ashley Guidroz (419) 372.8238 aguidro@bgsu.edu

Scott Highhouse (419) 372.8018 shighho@bgsu.edu 
Table 1 Description of Sample

\begin{tabular}{|c|c|c|c|}
\hline \multicolumn{2}{|l|}{ Gender } & Age & $39.60(11.05)$ \\
\hline Male & 41 & Years Worked & $18.03(11.64)$ \\
\hline Female & 59 & Education Level & \\
\hline Race/Ethnicity & & Less than high school & 1 \\
\hline Caucasian & 72 & High School & 17 \\
\hline African-American & 4 & Associates Degree & 11 \\
\hline Hispanic & 2 & Some College & 17 \\
\hline Asian/Pacific Islander & 15 & Bachelors Degree & 27 \\
\hline Arabic/Middle-Eastern & 1 & Some Graduate School & 4 \\
\hline Other & 6 & Masters Degree & 9 \\
\hline U.S. Resident & & Advanced Degree & 2 \\
\hline Yes & 51 & Top 5 Occupations & \\
\hline No & 40 & Administration Support & 10 \\
\hline Missing & 9 & Education/Training & 9 \\
\hline \multicolumn{2}{|l|}{ Employment Situation } & Health or Safety & 7 \\
\hline Full-Time & 63 & Technology & 7 \\
\hline Part-Time & 23 & Accounting/Financial & 6 \\
\hline Missing & 14 & & \\
\hline
\end{tabular}

Note. Numbers in columns are percentage of sample with the exception of Age and Tenure, which are averages; Standard deviation in parentheses. 
Table 2 Results of Principal Axis Factoring on Dependent Variables

\begin{tabular}{l|rr}
\hline & \multicolumn{2}{c}{ Factor } \\
\cline { 2 - 4 } Item & \multicolumn{2}{c}{2} \\
\hline The company's efforts to increase [type] diversity have been successful. & $\mathbf{. 8 9 8}$ & .062 \\
This company has achieved an optimal level of [type] diversity. & $\mathbf{. 8 8 9}$ & .129 \\
Outsiders would view this company as diverse. & $\mathbf{- . 5 6 7}$ & -.207 \\
I think this company should make more effort to increase [type] diversity.* & $\mathbf{. 3 8 5}$ & .170 \\
This is not what I think of when I think about workplace diversity.* & .032 & $\mathbf{. 8 6 2}$ \\
I think people mean something else when they use the word "diversity".* & -.097 & $\mathbf{. 8 5 0}$ \\
This is not really diversity.* & .153 & $\mathbf{. 6 6 7}$ \\
\hline
\end{tabular}

Note. Factor 1 is Diversity Management Efforts; Factor 2 is Conception of Diversity. *Items were re-coded for hypothesis testing. 
Table 3 Means, Standard Deviations, and Intercorrelations between Study Variables

\begin{tabular}{|c|c|c|c|c|c|c|c|c|c|c|c|c|}
\hline & $\mathrm{M}$ & SD & 1 & 2 & 3 & 4 & 5 & 6 & 7 & 8 & 9 & 10 \\
\hline 1. Residency & 1.44 & .50 & -- & & & & & & & & & \\
\hline 2. Age & 3.44 & 1.18 & -.06 & -- & & & & & & & & \\
\hline 3. Gender & 1.59 & .49 & $-.19 * *$ & .09 & -- & & & & & & & \\
\hline 4. Race & 1.28 & .45 & $.13^{*}$ & $-.25 * *$ & $-.24 * *$ & -- & & & & & & \\
\hline 5. Tenure & 18.03 & 11.64 & -.08 & $.75^{* *}$ & .06 & $-.30 * *$ & -- & & & & & \\
\hline 6. Edu. Level & 4.24 & 1.62 & .02 & -.06 & $-.12 *$ & $.17 * *$ & $-.12 *$ & -- & & & & \\
\hline 7. Conception of Diversity & 2.55 & .87 & -.03 & $-.13 * *$ & -.09 & .08 & $-.19 * *$ & .09 & -- & & & \\
\hline 8. Diversity Effort & 2.95 & .77 & .03 & $-.12 *$ & -.08 & .01 & -.09 & .01 & $.48 * *$ & -- & & \\
\hline 9. Optimal Amount & 52.11 & 17.47 & .03 & -.03 & -.05 & $.14^{* *}$ & -.01 & .07 & -.02 & -.01 & -- & \\
\hline 10. U.S. Pop Women & 54.42 & 9.77 & -- & $.23 * *$ & $.25^{* *}$ & -.14 & .13 & -.01 & $-.16^{*}$ & -.03 & .13 & -- \\
\hline 11. U.S. Pop. Race Minority & 42.02 & 17.07 & -- & .11 & $.17 *$ & -.08 & .06 & -.02 & -.01 & -.07 & .06 & $.30 * *$ \\
\hline
\end{tabular}

Note. ${ }^{*} p<.05 ; * * p<.01$. Residency, Gender, and Race are dummy variables wherein U.S. Residency, Males, and Whites $=1$, Non-

U.S. Resident, Females, and Racial Minorities $=2$. Correlations for Estimates of the U.S. Population that are Women and Racial

Minority include U.S. Residents only $(\mathrm{n}=197)$. 
Table 4 Summary of Analysis of Covariance for Judgments on Conception of Diversity

\begin{tabular}{lcccc}
\hline Source & $\mathrm{df}$ & $\mathrm{F}$ & $\eta$ & $\mathrm{P}$ \\
\hline Age & 1 & $7.45^{* *}$ & .02 & .01 \\
Gender & 1 & 1.53 & .00 & .22 \\
Race & 1 & .21 & .00 & .65 \\
Type (A) & 1 & $15.25^{* *}$ & .04 & .01 \\
Amount (B) & 2 & 2.47 & .01 & .09 \\
Frame (C) & 1 & $5.19^{*}$ & .01 & .02 \\
A x B & 2 & .47 & .00 & .62 \\
A x C & 1 & $6.15^{* *}$ & .02 & .01 \\
B x C & 2 & .52 & .00 & .59 \\
A x B x C & 2 & .20 & .00 & .82 \\
Error & 368 & $(.59)$ & & \\
\hline
\end{tabular}

Note. Value in parentheses represent mean square error. $* p<.05 . * * p<.01$. 
Table 5 Cell Means for Information Frame and Diversity Type on Conception of Diversity Minority Frame Non-Minority Frame

\begin{tabular}{rcc}
\hline Gender Diversity & & \\
$M$ & 2.36 & 2.39 \\
$S D$ & .64 & .73 \\
$n$ & 99 & 90 \\
Racial Diversity & & \\
& & \\
$M$ & 2.88 & 2.47 \\
$S D$ & .89 & .81 \\
$n$ & 107 & 89 \\
\hline
\end{tabular}


Table 6 Summary of Analysis of Covariance for Judgments on Diversity Management Efforts

\begin{tabular}{lcccc}
\hline Source & df & $\mathrm{F}$ & $\eta$ & $\mathrm{P}$ \\
\hline Age & 1 & $4.73^{*}$ & .01 & .03 \\
Gender & 1 & 1.50 & .00 & .22 \\
Race & 1 & .79 & .00 & .38 \\
Type (A) & 1 & 1.86 & .01 & .17 \\
Amount (B) & 2 & $8.59 * *$ & .05 & .00 \\
Frame (C) & 1 & $6.70^{* *}$ & .02 & .01 \\
A x B & 2 & 2.01 & .01 & .14 \\
A x C & 1 & $8.45^{* *}$ & .02 & .00 \\
B x C & 2 & 1.30 & .01 & .27 \\
A x B x C & 2 & .01 & .00 & .99 \\
Error & 364 & $(.48)$ & &
\end{tabular}

Note. Value in parentheses represent mean square error. ${ }^{*} p<.05 .{ }^{*} * p<.01$. 
Table 7 Tests of Linear and Quadratic Trends of Amount of Diversity on Diversity Management

\section{Efforts}

\begin{tabular}{lccc}
\hline Source & df & F & P \\
\hline Linear Term & 1 & .25 & .62 \\
Quadratic Term & 1 & $13.92 * *$ & .00 \\
Error & 378 & $(.51)$ &
\end{tabular}

Note. Value in parentheses represent mean square error. ${ }^{*} p<.05 . * * p<.01$. 
Table 8 Cell Means of Information Frame and Diversity Type on Diversity Management Effort

\begin{tabular}{|c|c|c|}
\hline & Minority Frame & Non-Minority Frame \\
\hline \multicolumn{3}{|l|}{ Gender Diversity } \\
\hline$M$ & 2.86 & 2.96 \\
\hline$S D$ & .65 & .76 \\
\hline$n$ & 97 & 90 \\
\hline \multicolumn{3}{|l|}{ Racial Diversity } \\
\hline$M$ & 3.19 & 2.78 \\
\hline$S D$ & .70 & .72 \\
\hline$n$ & 106 & 88 \\
\hline
\end{tabular}


Table 9 Mean Estimates of U.S. Population Base-Rates by Condition

\begin{tabular}{|c|c|c|}
\hline & U.S. Population & U.S. Population \\
\hline & Female & Racial Minority \\
\hline \multicolumn{3}{|l|}{ Gender Diversity } \\
\hline$M$ & 56.13 & 44.06 \\
\hline$S D$ & 11.28 & 17.61 \\
\hline$n$ & 101 & 101 \\
\hline \multicolumn{3}{|l|}{ Racial Diversity } \\
\hline$M$ & 53.33 & 42.53 \\
\hline$S D$ & 7.09 & 16.62 \\
\hline$n$ & 91 & 91 \\
\hline \multicolumn{3}{|l|}{ Total Sample } \\
\hline$M$ & 54.80 & 43.33 \\
\hline$S D$ & 9.61 & 17.13 \\
\hline$n$ & 192 & 192 \\
\hline
\end{tabular}

Note. Values reported are mean percentages. 
Table 10 Summary of Analysis of Covariance for Judgments of Diversity Management Efforts with Estimates of Population Base-Rates Included as Covariates

\begin{tabular}{lcccc}
\hline Source & df & F & $\eta$ & P \\
\hline Age & 1 & $5.10^{*}$ & .02 & .03 \\
Gender & 1 & 1.82 & .00 & .18 \\
Race & 1 & .88 & .00 & .35 \\
Estimates of Women & 1 & 1.59 & .01 & .21 \\
Estimates of Racial Minorities & 1 & 2.17 & .01 & .14 \\
Type (A) & 1 & 1.69 & .01 & .19 \\
Amount (B) & 2 & $8.07^{* *}$ & .05 & .00 \\
Frame (C) & 1 & $8.51^{* *}$ & .03 & .00 \\
A x B & 2 & 1.79 & .01 & .17 \\
A x C & 1 & $7.54^{* *}$ & .02 & .01 \\
B x C & 2 & 1.55 & .01 & .21 \\
A x B x C & 2 & .05 & .00 & .95 \\
Error & 364 & $(.49)$ & & \\
\hline
\end{tabular}

Note. Value in parentheses represent mean square error. $* p<.05 . * * p<.01$. 
Figure 1 Graph of Interaction between Type of Diversity and Information Frame on Conception of Diversity

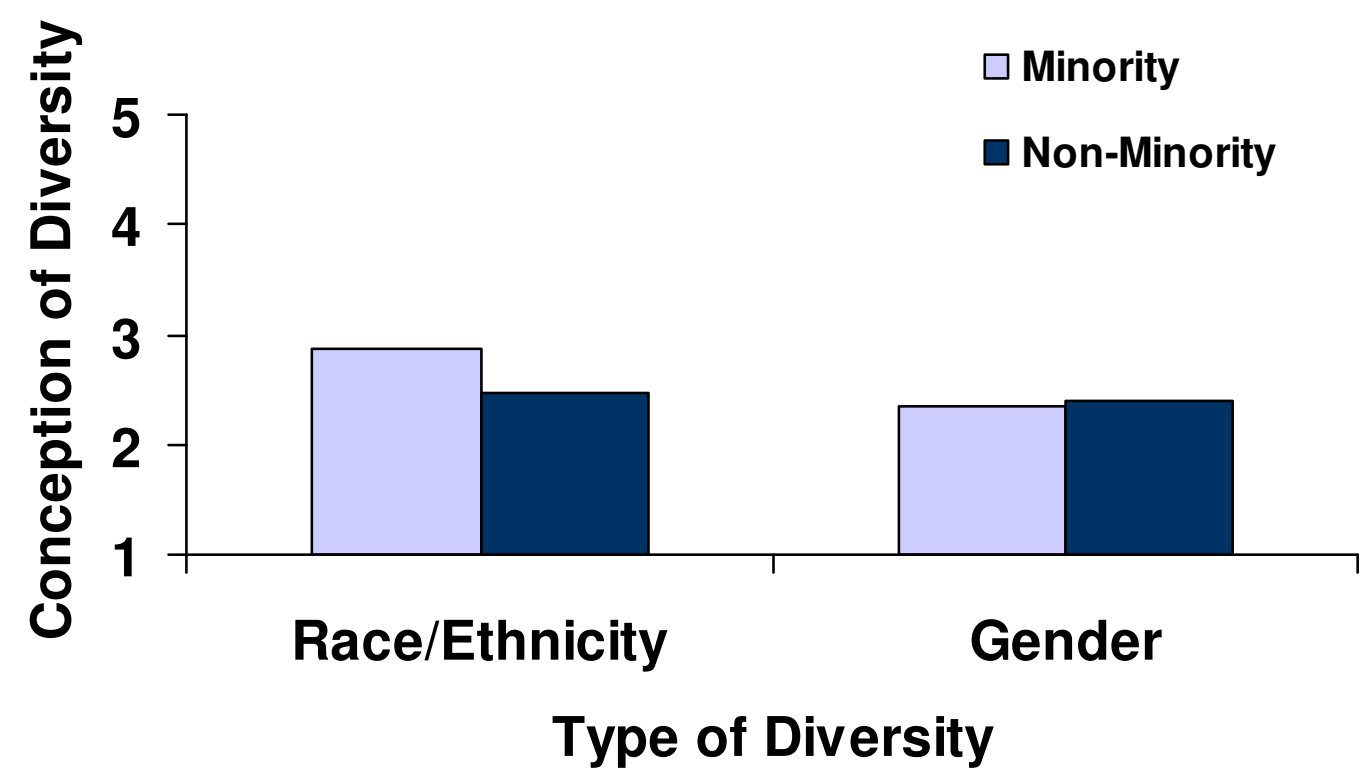


Figure 2 Graph of Main Effect of Amount of Diversity on Diversity Management Effort

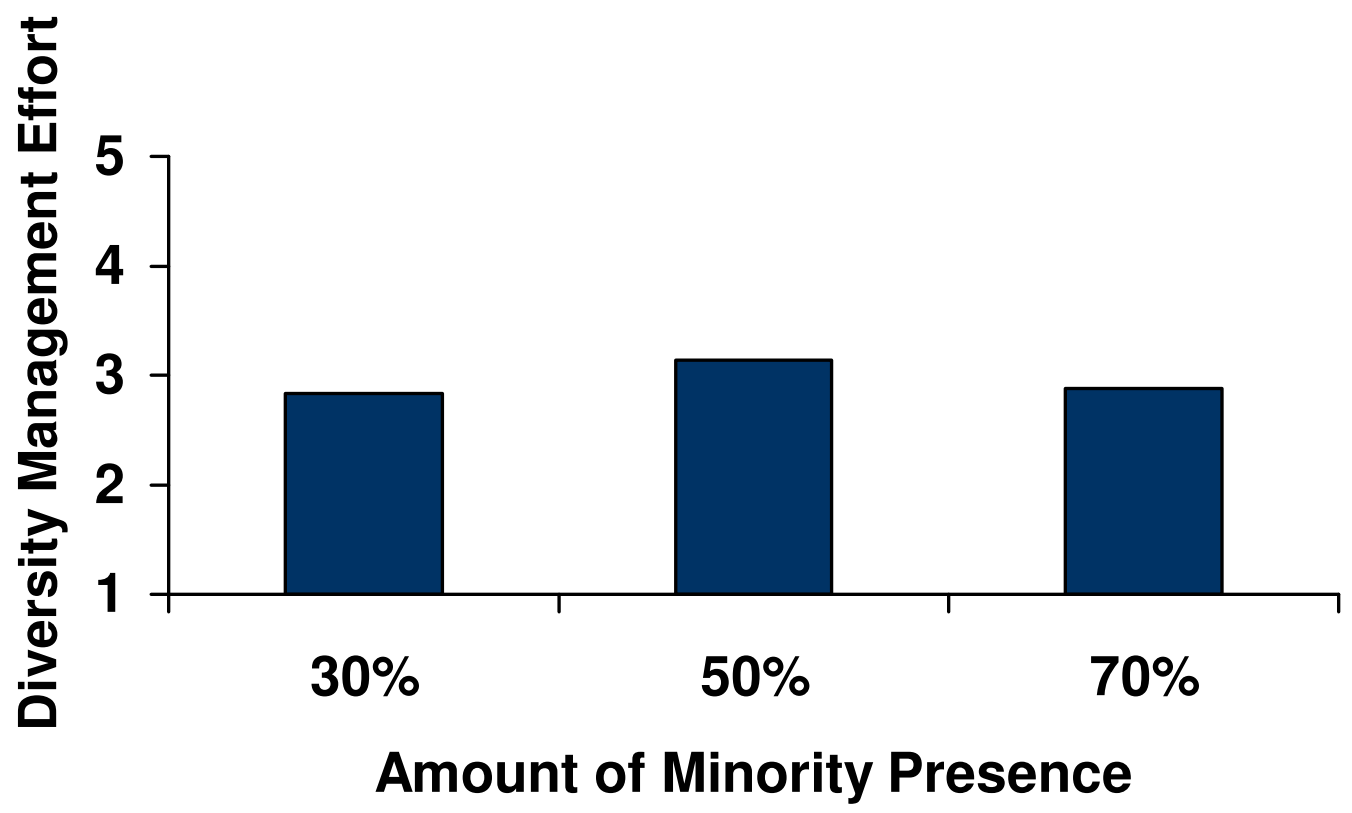


Figure 3 Graph of Interaction between Type of Diversity and Information Frame on Diversity Management Effort

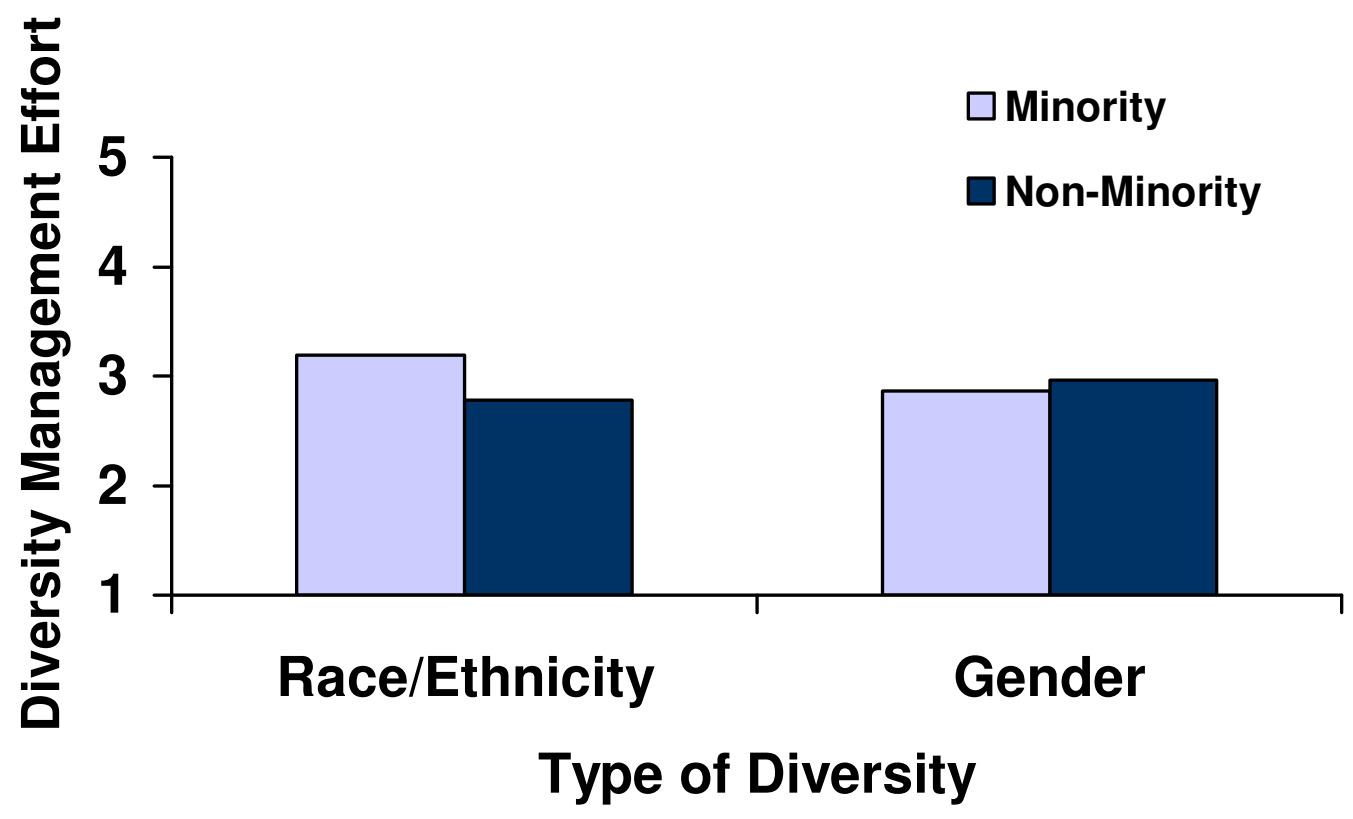

